\title{
Analysis of Localized Deformation
} Processes in Highly Irradiated Austenitic Stainless Steel through In Situ Techniques

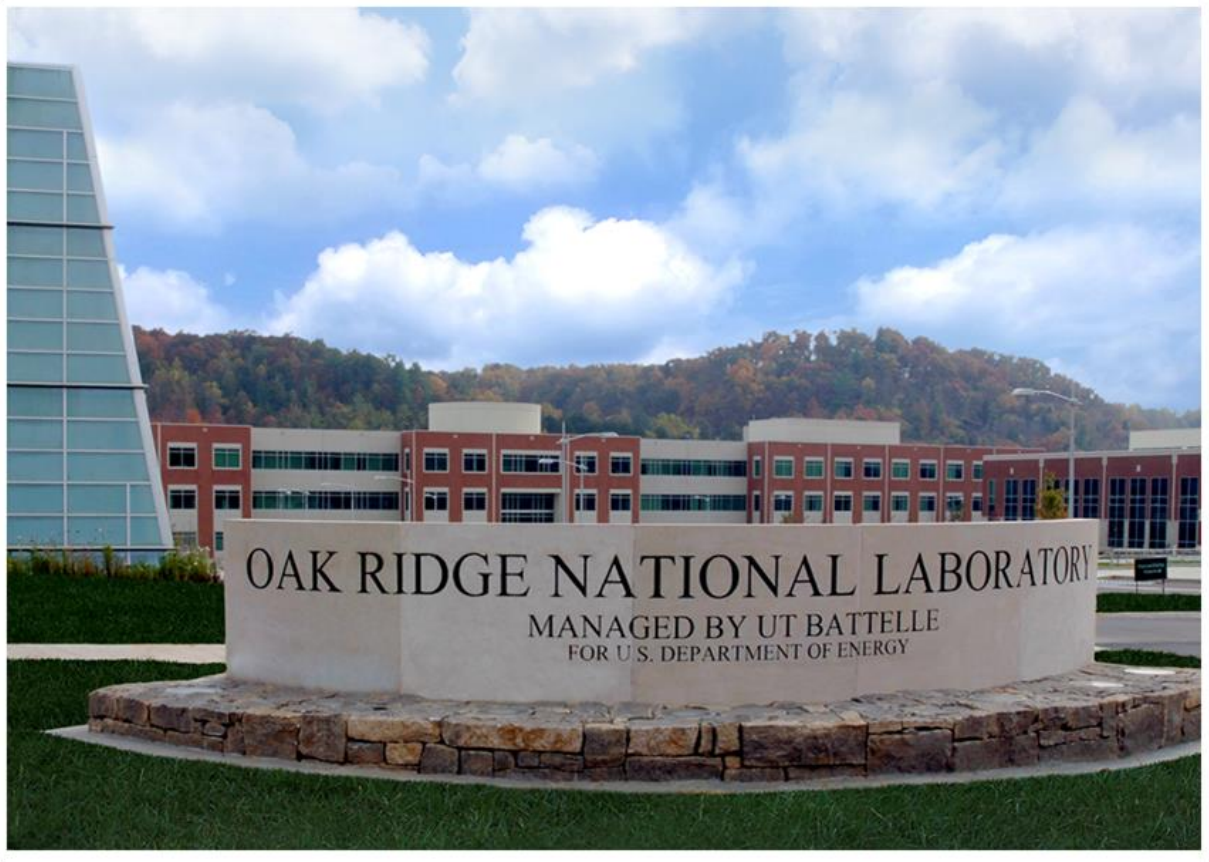

\section{Approved for public release.} Distribution is unlimited.
M. N. Gussev

G. Meric de Bellefon

T. M. Rosseel

August 2019 


\section{DOCUMENT AVAILABILITY}

Reports produced after January 1, 1996, are generally available free via US Department of Energy (DOE) SciTech Connect.

Website http://www.osti.gov/scitech/

Reports produced before January 1,1996, may be purchased by members of the public from the following source:

National Technical Information Service

5285 Port Royal Road

Springfield, VA 22161

Telephone 703-605-6000 (1-800-553-6847)

TDD 703-487-4639

Fax 703-605-6900

E-mail info@ntis.gov

Website http://classic.ntis.gov/

Reports are available to DOE employees, DOE contractors, Energy Technology Data Exchange representatives, and International Nuclear Information System representatives from the following source:

Office of Scientific and Technical Information

PO Box 62

Oak Ridge, TN 37831

Telephone 865-576-8401

Fax 865-576-5728

E-mail reports@osti.gov

Website http://www.osti.gov/contact.html

This report was prepared as an account of work sponsored by an agency of the United States Government. Neither the United States Government nor any agency thereof, nor any of their employees, makes any warranty, express or implied, or assumes any legal liability or responsibility for the accuracy, completeness, or usefulness of any information, apparatus, product, or process disclosed, or represents that its use would not infringe privately owned rights. Reference herein to any specific commercial product, process, or service by trade name, trademark, manufacturer, or otherwise, does not necessarily constitute or imply its endorsement, recommendation, or favoring by the United States Government or any agency thereof. The views and opinions of authors expressed herein do not necessarily state or reflect those of the United States Government or any agency thereof. 


\title{
Analysis of Localized Deformation Processes in Highly Irradiated Austenitic Steel through In Situ Techniques
}

\author{
M. N. Gussev \\ G. Meric de Bellefon \\ T. M. Rosseel
}

Date Published: August 2019

Prepared under the direction of the

U.S. Department of Energy

Office of Nuclear Energy

Light Water Reactor Sustainability Program

Materials Research Pathway

Prepared by

OAK RIDGE NATIONAL LABORATORY

Oak Ridge, TN 37831-6285

managed by

UT-BATTELLE, LLC

for the

U.S. DEPARTMENT OF ENERGY

under contract DE-AC05-00OR22725 
(This page intentionally left blank) 


\section{CONTENTS}

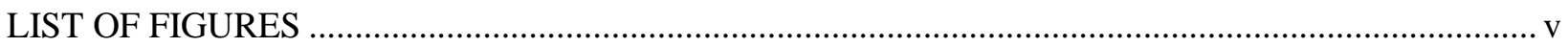

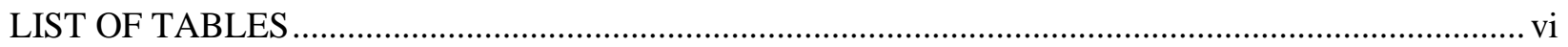

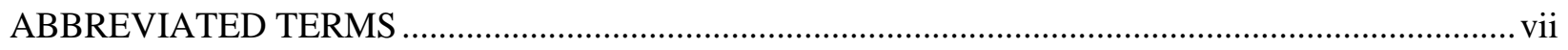

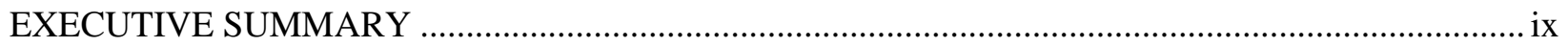

1. QUANTITATIVE ANALYSIS OF DEFORMATION LOCALIZATION IN IRRADIATED

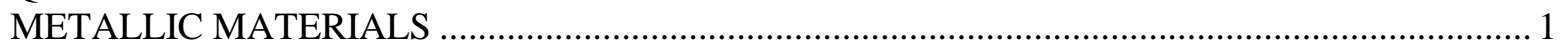

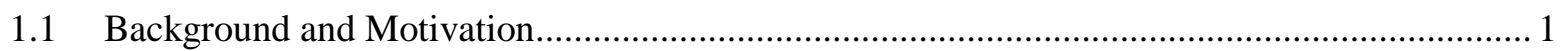

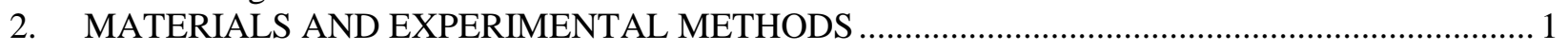

2.1 SEM/EBSD system and miniature tensile frame for in situ testing ..................................... 1

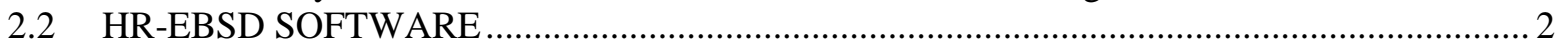

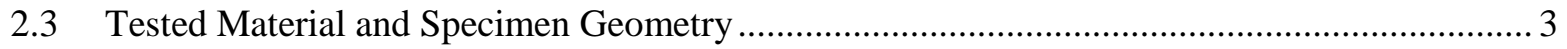

3. MECHANICAL IN SITU TEST TO INVESTIGATE GND EVOLUTION DURING

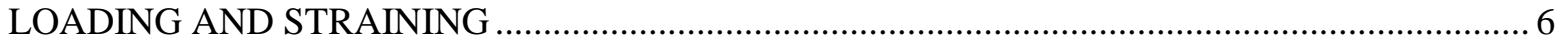

3.1 Tensile curves for the tested specimens ........................................................................ 6

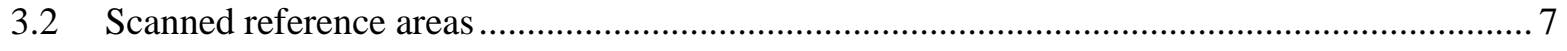

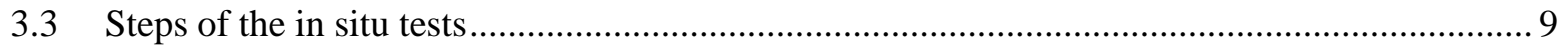

4. EVOLUTION OF GEOMETRICALLY NECESSARY DISLOCATION: HR-EBSD

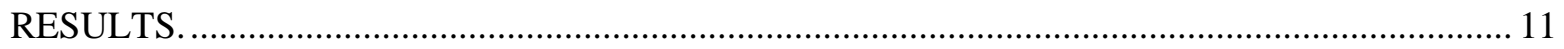

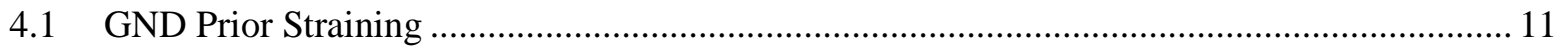

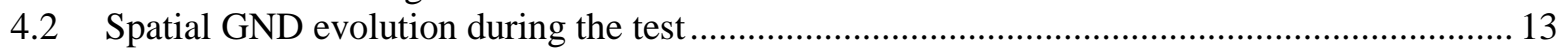

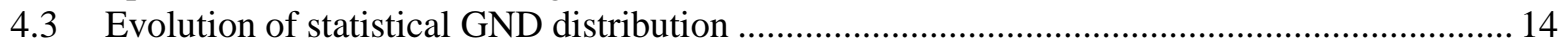

5. STUDYING CHANNEL-GRAIN BOUNDARY INTERACTION VIA HR-EBSD

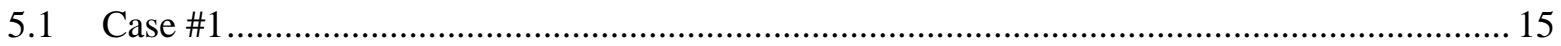

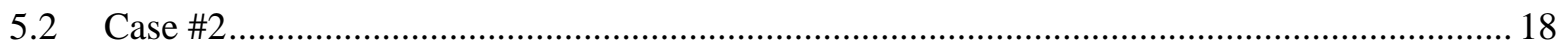

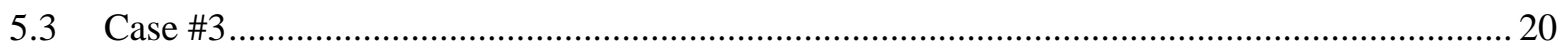

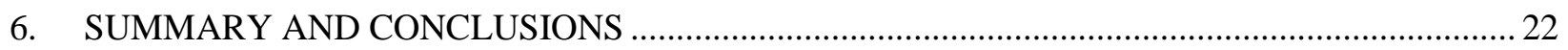

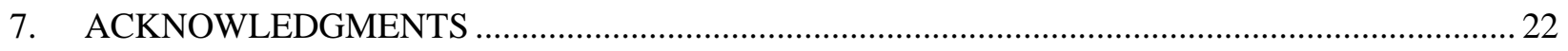

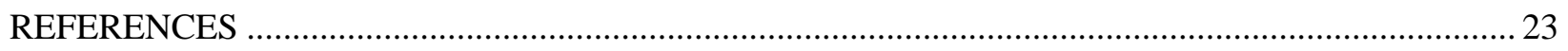


(This page intentionally left blank) 


\section{LIST OF FIGURES}

Figure 1. (Left top) General view of the TESCAN MIRA3 SEM. (Right top) Kammrath \& Weiss tensile stage prepared for in situ tensile testing; note the SEM stage was tilted at $-70^{\circ} \mathrm{C}$ to allow for safe and convenient specimen loading into the grips. (Middle bottom) Chamber interior with the stage in working position and EBSD camera fully inserted....

Figure 2. Irradiated material microstructure: inverse pole figure (IPF) map (left) and phase map (right). Steel contained $\sim 1.5-2 \%$ of retained ferrite, forming specific bands in the structure. IPF map is colored in the horizontal direction (tensile direction).

Figure 3. EDM-manufactured miniature tensile specimen blank. Gauge dimensions: $2 \mathrm{~mm}$ (length) $\times 0.8 \mathrm{~mm}$ (width) $\times 0.5 \mathrm{~mm}$ (thickness).

Figure 4. A $70^{\circ}$ tilted tensile specimen in the grips (left, no tilt correction applied) and backscatter electron (BSE) image of the specimen surface prior to the testing (right, software tilt correction employed). The BSE image was taken by an EBSD camera on a frontscatter electron detector. One may see a flat clean object surface with few dust and debris particles.

Figure 5. Typical appearance of the electropolished surface (SE detector). One may see few inclusions (Inc), carbon contamination spots $(\mathrm{C})$, and string-like inclusion of ferrite $(\mathrm{F}$, which is visible due to different sensitivity to the A2 electropolishing solution). Note the image is $70^{\circ}$ tilted with tilt correction applied.

Figure 6. Left: Typical Kikuchi pattern for nondeformed irradiated steel. Right: A pattern for nondeformed reference $304 \mathrm{~L}$ steel.

Figure 7. Tensile curves obtained during in situ tests with nonirradiated reference specimens (Refs., green) and irradiated ones (Irr.\#1 and Irr.\#2, blue and red, respectively), damage dose $10.7 \mathrm{dpa}$. Square symbols show the test interruptions to perform EBSD scans. An example of the ex situ test (the same geometry specimen tested continuously, without interruptions) is also given for comparison.

Figure 8. Grain maps (EBSD IPF figures) of typical ROIs for the tested specimens. Note the difference in the magnification and scale for the left and right columns. One may see that grain morphology is close enough between irradiated and reference specimens.

Figure 9. BSE image of a typical ROI (reference specimen). BSE imaging is a convenient tool to evaluate grain morphology and surface quality within the potential ROI.

Figure 10. A scheme of a typical in situ test. Square symbols show stops to perform EBSD scanning. Note the same specimen may yield data for a wide range of stresses and strains.

Figure 11. Strain-induced surface morphology in the 10.7 dpa irradiated 304L steel. Despite the interesting appearance, EBSD data interpretation is complicated at such strain levels. Note the images are $70^{\circ}$ tilted with tilt correction applied; high-tilt angle increases the height/depth perception.

Figure 12. GND map for a typical ROI. Note the logarithmic scale (dimensions: $\mathrm{m}^{-2}$ ). Black arrows mark GBs with high GND density. Dashed oval shows an area with slightly increased GND values in the grain interior and at the GBs.

Figure 13. Histogram of GND density distribution, presented using the logarithm scale, in the specimen prior to straining. The GND distribution may be described by two Gauss-like functions (labeled as \#1 and \#2), corresponding to the different types of dislocation substructures (e.g., chaotic distribution of dislocations and dislocation walls).

Figure 14. Average GND density for the ROI, shown in Figure 15, as a function of stress and plastic strain.

Figure 15. Spatial GND evolution inside a typical ROI during in situ testing. The scale is the same for all maps within the figure. 
Figure 16. Histogram of GND density at different steps of the in situ test (see the tensile curve in Figure 10). Black arrow indicates a weak increased local GND associated with hot spots; its location $\left[\log _{10}(G N D) ~ 14.6\right]$ and amplitude were close for the analyzed stress/strain range

Figure 17. Location \#1. DC: dislocation channels. $\mathrm{G}_{1}, \mathrm{G}_{2}$ : grains within the subarea scan; $\mathrm{Ch}$ : channel hitting the boundary between $\mathrm{G}_{1}$ and $\mathrm{G}_{2}$. Dashed rectangle approximately shows the subarea scanned with $125 \mathrm{~nm}$ step.

Figure 18. EBSD maps for the subarea, shown in Figure 17.

Figure 19. HR-EBSD maps for the channel (Ch)-grain boundary (GB) interaction (location \#1, also see Figure 17 and Figure 18). $\sigma_{11}$ shows stress in the tensile direction (horizontal)

Figure 20. GND map for location \#1. Note this map has a $125 \mathrm{~nm}$ step size, so it cannot be directly compared with Figure 15, which has a different EBSD step size.................................. 17

Figure 21. Spatial vs. statistical distribution of the stress values...................................................... 18

Figure 22. EBSD dataset for the case \#2. TA: tensile axis. A few points located close to GBs were not indexed properly due to the partial pattern overlapping.

Figure 23. HR-EBSD dataset (elastic stresses, calculated by CrossCourt4 software) for case \#2.

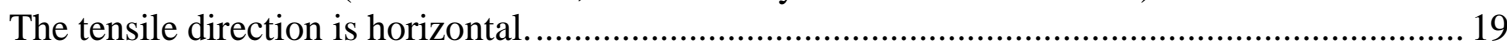

Figure 24. GND map for the area shown in Figure 22 and Figure 23................................................... 20

Figure 25. Conventional EBSD maps showing IPF, IQ, and GROD map for the Case \#3 location........... 21

Figure 26. Pattern degradation inside strain localization areas as an issue. Pattern quality may vary drastically within one to two steps $(125-250 \mathrm{~nm})$.

\section{LIST OF TABLES}

Table 1. Composition (wt \%) and grain size for the investigated material 3 


\section{ABBREVIATED TERMS}

$\begin{array}{ll}\text { BSE } & \text { back-scatter electron } \\ \text { dpa } & \text { displacement per atom } \\ \text { EBSD } & \text { electron backscatter diffraction } \\ \text { EDM } & \text { electrical discharge machine } \\ \text { fcc } & \text { face-centered cubic } \\ \text { GB } & \text { grain boundary } \\ \text { GND } & \text { geometrically necessary dislocation } \\ \text { GROD } & \text { grain reference orientation deviation } \\ \text { HR-EBSD } & \text { high resolution (or high angular resolution) electron backscatter diffraction } \\ \text { IPF } & \text { Inverse pole figure } \\ \text { LAMDA } & \text { Low Activation Materials Development and Analysis facility } \\ \text { LWR } & \text { light water reactor } \\ \text { NAS } & \text { Network attached storage. } \\ \text { ORNL } & \text { Oak Ridge National Laboratory } \\ \text { RAID } & \text { redundant array of independent disks } \\ \text { ROI } & \text { region of interest } \\ \text { SE } & \text { secondary electron } \\ \text { SEM } & \text { scanning electron microscope/microscopy } \\ \text { SSD } & \text { stochastically stored dislocations } \\ \text { TEM } & \text { transmission electron microscope/microscopy }\end{array}$


(This page intentionally left blank) 


\section{EXECUTIVE SUMMARY}

This report describes new experimental results obtained during in situ mechanical tests with neutronirradiated (10.7 dpa) austenitic 304L steel specimens. The in situ tensile tests inside a scanning electron microscope (SEM) were accompanied by modern high-resolution electron backscatter diffraction (HREBSD) analysis. The HR-EBSD approach allowed for investigating and quantifying internal stresses and dislocation structures in nondeformed and deformed steels, materials used in light water reactor internal components. The literature regarding the HR-EBSD analysis of metals and alloys is very limited, and practically no publications on the HR-EBSD analysis coupled with in situ tests are available.

Experimental work, performed at Oak Ridge National Laboratory's Low Activation Materials Development and Analysis facility, is detailed in this report. Section 1 briefly describes strain and stress localization processes and underlines their importance and role in irradiated materials, materials used in nuclear power plants. The section demonstrates that very limited quantitative data exist regarding localized stresses and strains in the irradiated materials at the meso-level (i.e., inside the grain, for a group of interacting grains, or for channel-grain boundary [GB] interaction) whereas local stresses at GBs are key contributors to the stress corrosion crack initiation.

Section 2 documents the key methods used to conduct the experimental work: the SEM/EBSD system, miniature tensile frame, and irradiated material. Irradiated specimen manufacturing is described, as this option may be of special interest for other projects. Section 3 provides details of the HR-EBSD in situ tests (e.g., tensile curves, geometry, dimensions of regions of interest, load, and deformation steps). Section 4 discusses the results related to the evolution of geometrically necessary dislocations (GNDs) and their density, spatial, and statistical distributions.

Section 5 focuses on the HR-EBSD analysis with respect to a channel-GB interaction. Two aspects are discussed in detail: mapping and analyzing the GND fields before and after loading, and the possibility of investigating local stresses and elastic strains at the channel-GB interaction. The present work results are beneficial for understanding strain and stress localization processes leading to crack initiation, for analyzing the material after long-term in-service life, and for developing predictive models. Section 6 summarizes the work performed and discusses future activities within this research direction. 
(This page intentionally left blank) 


\section{QUANTITATIVE ANALYSIS OF DEFORMATION LOCALIZATION IN IRRADIATED METALLIC MATERIALS}

\subsection{Background and Motivation}

It is well known that dislocation pileups at the slip line-grain boundary (GB) interaction point generate elevated local stresses [1,2]; this finding was confirmed via experimental measurements using synchrotron irradiation [3]. The presence of areas with high local stresses influences material performance processes including fatigue, fracture, and cracking. Dislocation channel formation and the appearance of dislocation pileups [2] may directly preclude stress corrosion crack initiation [4-6]. It has also been demonstrated that dislocation channel formation may occur at external stresses below yield stress [7,8], so it is important to understand dislocation evolution under these conditions.

The complexity of the experimental setup, however, has not allowed for routine in-grain stress measurements at the lab scale during common mechanical tests. This changed recently when a number of modern techniques came into use. One of these techniques is high-resolution electron backscatter diffraction (HR-EBSD, often called high angular resolution EBSD) analysis [9,10]. The HR-EBSD technique allows for evaluating the in-grain elastic stresses (i.e., Type III internal stresses) and density of geometrically necessary dislocation (GND) with spatial resolution as high as $\sim 100 \mathrm{~nm}$. HR-EBSD analysis is an actively growing area. It generates interesting results [10-12], attracts some criticism, and demonstrates ongoing development and improvement [13]. A limited set of papers on the HR-EBSD analysis of steels and metallic alloys [10-12,14,15] is available, including a few publications on ex situ analysis of irradiated steels and alloys [16,17]. For instance, it was confirmed recently using HR-EBSD [16] that high local stresses, associated with dislocation pileup, stimulate crack initiation in a simulated light water reactor (LWR) environment.

The present work employs the HR-EBSD technique to study the evolution of localized stresses and strains in the irradiated material in situ, under mechanical stress, during straining. As expected, this approach provides unique data on dislocation density and its evolution, allowing for a deep understanding of the complex strain localization processes as well as the distribution of in-grain stresses before and after straining. This knowledge is crucial for a mechanistic understanding of these phenomena and predictive model development. It is important to define and quantify parameters controlling or influencing corrosion processes in irradiated LWR-relevant material to connect these parameters to the material microstructure and performance.

\section{MATERIALS AND EXPERIMENTAL METHODS}

\subsection{SEM/EBSD system and miniature tensile frame for in situ testing}

A modern TESCAN MIRA3 (Figure 1) was purchased and installed in FY2018. This scanning electron microscope (SEM) is equipped with an advanced Oxford Symmetry EBSD system (detector resolution $1244 \times 1024$ pixels, EBSD indexing rate up to $\sim 200 \mathrm{~Hz}$ in full-frame mode, and $\sim 3.5 \mathrm{kHz}$ in $8 \times 8$ binning mode). The SEM has a slightly larger chamber compared to the VERSA 3D SEM, used previously [18], allowing for easier installation and operation of the Kammrath \& Weiss in situ tensile frame $[18,19]$. 

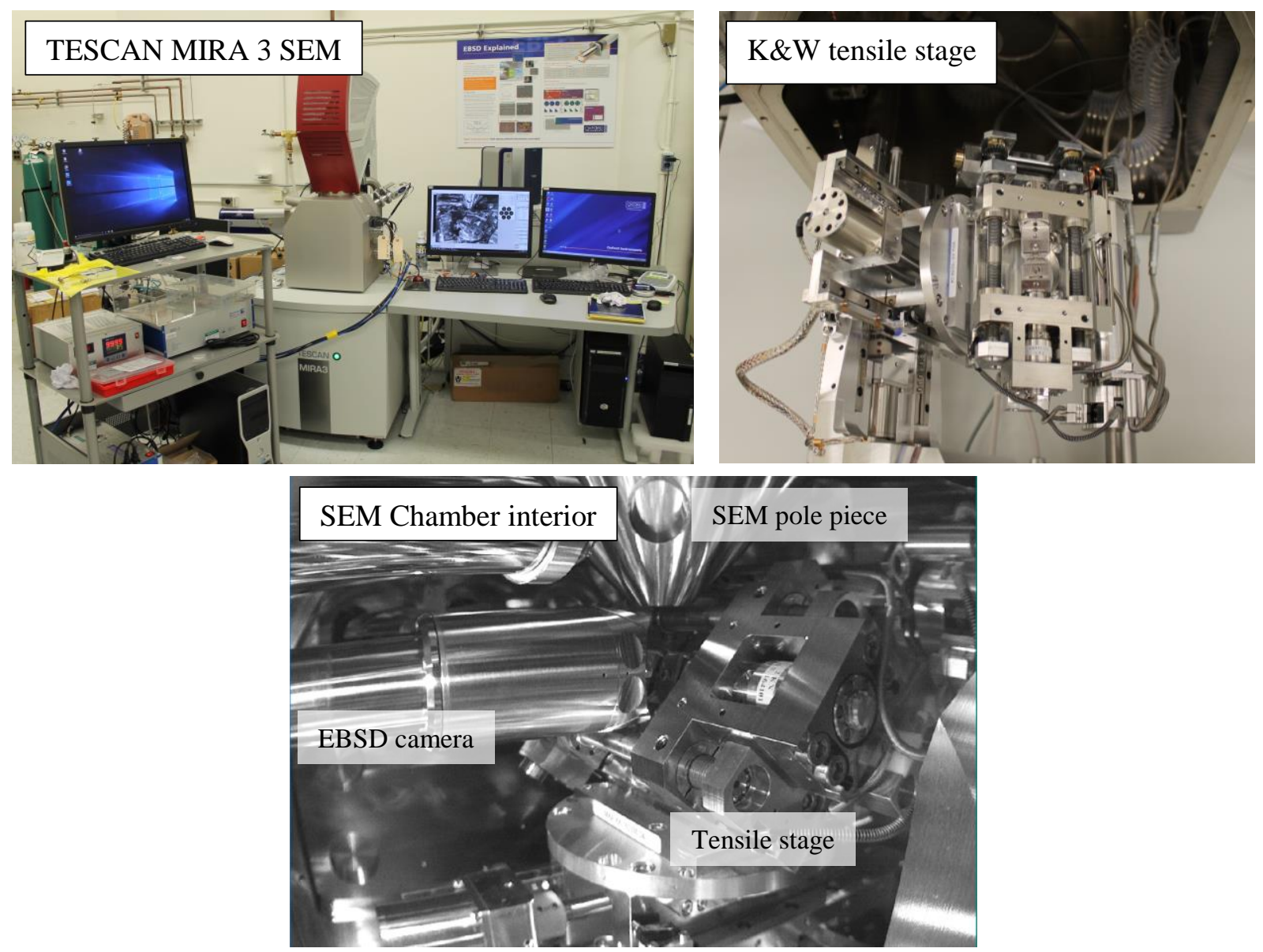

Figure 1. (Left top) General view of the TESCAN MIRA3 SEM. (Right top) Kammrath \& Weiss tensile stage prepared for in situ tensile testing; note the SEM stage was tilted at $-\mathbf{7 0}^{\circ} \mathrm{C}$ to allow for safe and convenient specimen loading into the grips. (Middle bottom) Chamber interior with the stage in working position and EBSD camera fully inserted.

For this SEM, the EBSD detector may be fully inserted (insertion distance $>175 \mathrm{~mm}$ ) when the tensile stage is installed in the chamber. It allows for recording Kikuchi patterns with a much larger solid angle, compared to the VERSA 3D SEM used earlier [18,19]. Whereas the pattern appearance (i.e., brightness, contrast, noise level) may depend on particular scan conditions, the increased solid angle is a significant advantage for use with HR-EBSD techniques, providing much better angular resolution.

\subsection{HR-EBSD SOFTWARE}

In the present work, the CrossCourt4 commercial software package was employed to perform HR-EBSD analyses (http://www.hrebsd.com/wp/crosscourt). CrossCourt4 has more flexibility and is easier to use compared to its open-source competitors. Data were processed using a dedicated NAS/RAID (networkattached storage/redundant array of independent disks) and a workstation with 12 cores and $96 \mathrm{~Gb}$ memory; this equipment is sufficient for processing a typical HR-EBSD dataset (e.g., 30,000-100,000 patterns, $40-100 \mathrm{~Gb}$ of data) within a reasonable timeframe (i.e., a few hours). 


\subsection{Tested Material and Specimen Geometry}

An AISI 304L austenitic stainless steel (high-purity custom heat with Ti addition) was selected for the experiment. Earlier it was demonstrated that highly irradiated 304L steel may show intense phase transformation at the surface [20]; however, in the present work, phase instability would be an unnecessary obstacle, complicating the analysis of strain and stresses. For the selected material, Ti addition and increased $\mathrm{Ni}$ amount ( $11.22 \%$ vs. $\sim 8-10 \%$ in common 304L steel) were expected to prevent (or at least delay) phase transformation and keep pure face-centered cubic (fcc) structure at small strains.

Table 1. Composition (wt \%) and grain size for the investigated material

\begin{tabular}{|c|c|c|c|c|c|c|c|c|c|c|}
\hline Material & $\mathbf{F e}$ & $\mathbf{C}$ & $\mathbf{M n}$ & $\mathbf{S i}$ & $\mathbf{C r}$ & $\mathbf{N i}$ & $\mathbf{M o}$ & $\mathbf{T i}$ & $\mathbf{N}$ & $\begin{array}{c}\text { Grain } \\
\mathbf{s i z e} \\
(\boldsymbol{\mu m})\end{array}$ \\
\hline $\begin{array}{c}\text { Modified } \\
\text { 304L }\end{array}$ & Bal. & 0.02 & 1.00 & 0.33 & 18.03 & 11.22 & 0.02 & 0.3 & 0.0005 & $\sim 10-15$ \\
\hline
\end{tabular}

The material studied in this work was produced for Cooperative Irradiation-Assisted Stress Corrosion Cracking Research (CIR) program [21] and irradiated in the BOR-60 fast reactor. The calculated damage dose was $10.7 \mathrm{dpa}$. The nominal element composition is given in Table 1 . One may see also that the selected material has a smaller grain size $(\sim 10-15 \mu \mathrm{m}$, Table 1$)$, compared to many commercial $304 \mathrm{~L}$ heats (e.g., 304L heat investigated earlier [19]).

For present work purposes, the small grain size was considered an advantage because it allows for collecting good statistics (e.g., 50-100 grains within the EBSD scan) while at the same time keeping the dataset size within manageable limits ( $\sim 100 \mathrm{~Gb}$ or below). Finding a reasonable compromise between the region of interest (ROI) dimensions, EBSD step (pitch) size, and number of in situ test steps may be not easy, because one has to record, transfer, and process multiple datasets for the same ROI (or multiple ROIs) for each stress and strain level. Total data amount may easily exceed a terabyte ( $\mathrm{Tb}$ ), requiring special software/hardware solutions and custom scripts.
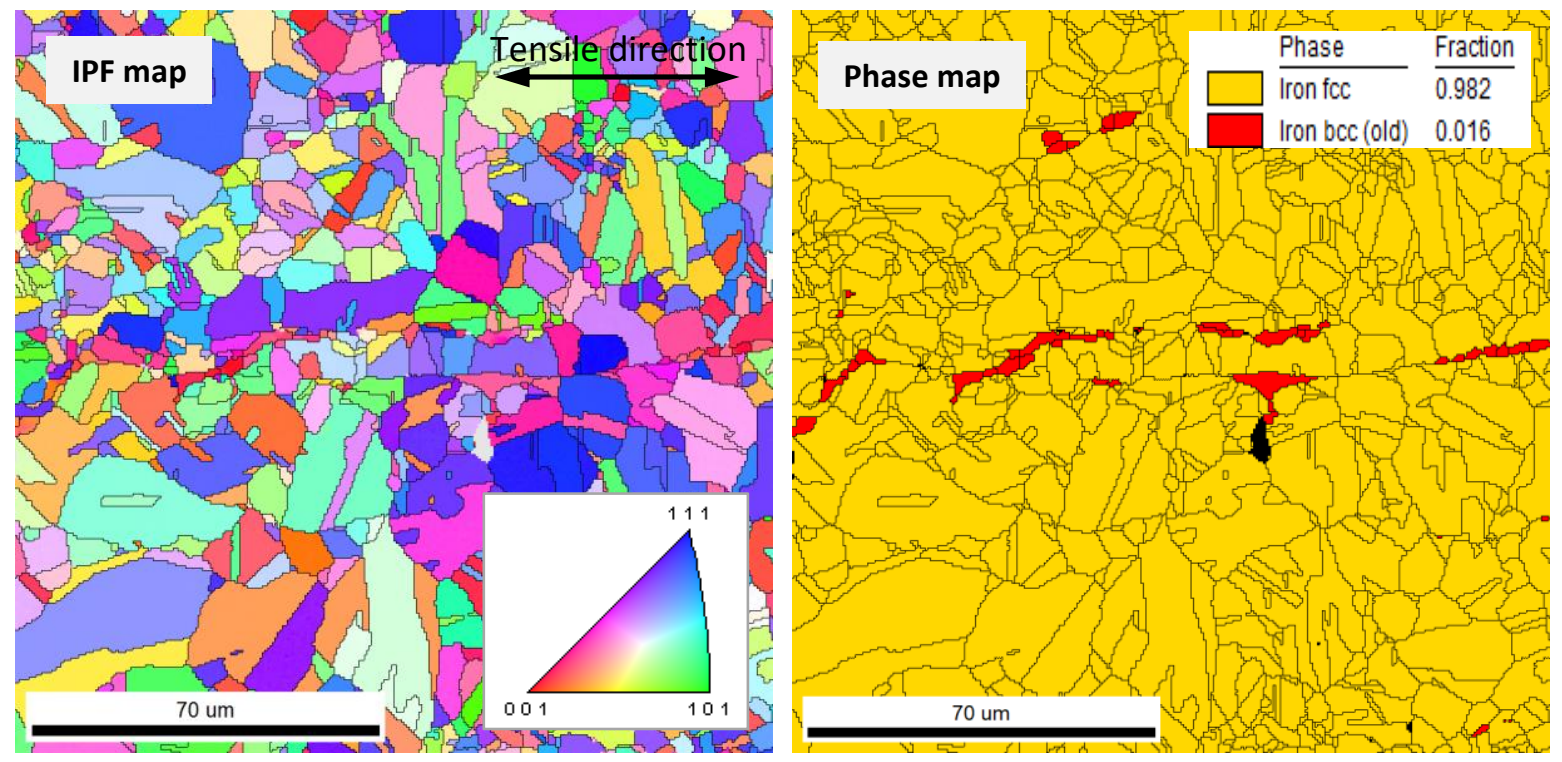

Figure 2. Irradiated material microstructure: inverse pole figure (IPF) map (left) and phase map (right). Steel contained $\sim 1.5-2 \%$ of retained ferrite, forming specific bands in the structure. IPF map is colored in the horizontal direction (tensile direction). 
Figure 2 shows the typical microstructure of the irradiated steel. One may see that small grains form specific clusters, surrounding large grains; the material has a bimodal grain distribution. The analysis showed no pronounced texture in the austenitic matrix.

A limited amount of ferrite $(<2 \%)$ presents in the structure. Ferrite grains appeared as bands or chains elongated in one direction - most likely, the former hot rolling direction. Based on the ferrite grain size and morphology, this body-centered cubic phase may be classified as retained delta-ferrite. The ferrite presence is not important for the present work purposes; however, the impact of the ferritic grains on their austenitic neighbors may be of interest in the future.

Miniature tensile specimens of the SS-Tiny geometry [18] were manufactured using the electrical discharge machine (EDM) located in Oak Ridge National Laboratory's (ORNL's) Low Activation Materials Development and Analysis facility and allowing for handling and processing irradiated materials. The cut specimen blank is shown in Figure 3. Electric discharge machining allows for much faster specimen manufacturing, compared to the Computer Numerical Control (CNC) system used earlier [18]. Electrical discharge machining also provides better accuracy and more flexibility regarding specimen geometry. However, the EDM-cut objects always contain an eroded and re-melted layer along the cut edge; in some cases, this layer may be not easy to remove. Additionally, EDM cutting of thin plates may be difficult because of intense water jets near the object, as water jets generate vibration, usually resulting in the wrong dimensions and the appearance of defects such as undercuts at the specimen edges. Thus, CNC machining still may be an option in the future.

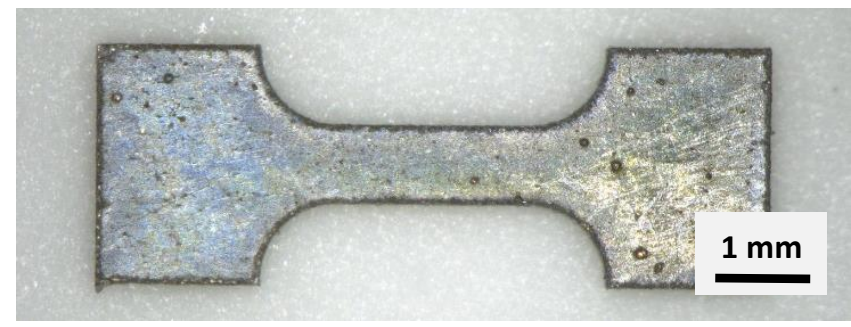

Figure 3. EDM-manufactured miniature tensile specimen blank. Gauge dimensions: $2 \mathrm{~mm}$ (length) $\times 0.8 \mathrm{~mm}$ (width) $\times 0.5 \mathrm{~mm}$ (thickness).

The specimen black was mechanically grinded, polished, and electropolished using A2 Struer solution. After the final electropolishing step, the miniature specimen had a clean, mirror-like surface suitable for EBSD analysis. In most cases, electropolishing also removed the EDM-induced layer at the specimen side surfaces and formed slightly rounded edges (Figure 4, right).

Figure 5 shows a secondary electron (SE) image of a typical electropolished surface. Usually, few inclusions present in the field of view, and ferrite grains (or domains) may be visible. Often, light carbon contamination appears after scanning and focusing operations instead of the plasma cleaning operation, always performed prior to and after tensile stage installation. 

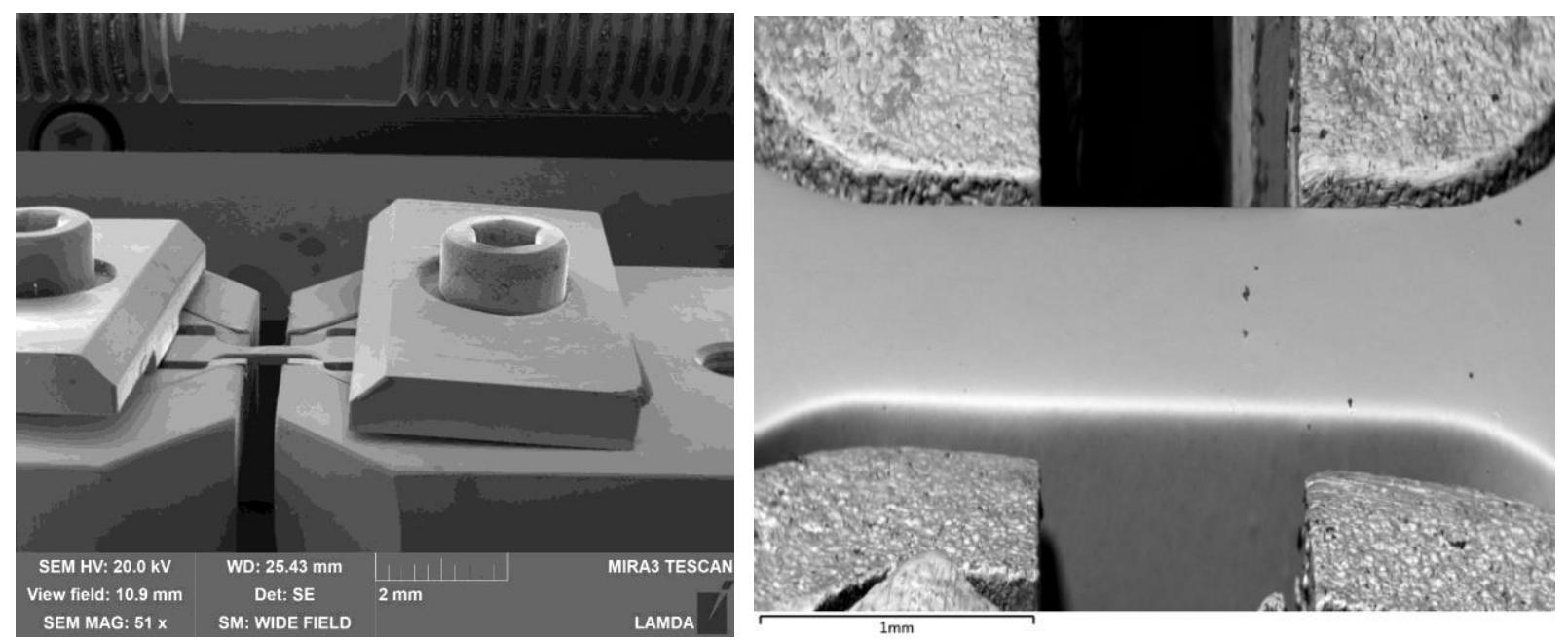

Figure 4. A 70 ${ }^{\circ}$ tilted tensile specimen in the grips (left, no tilt correction applied) and back-scatter electron (BSE) image of the specimen surface prior to the testing (right, software tilt correction employed). The BSE image was taken by an EBSD camera on a front-scatter electron detector. One may see a flat clean object surface with few dust and debris particles.

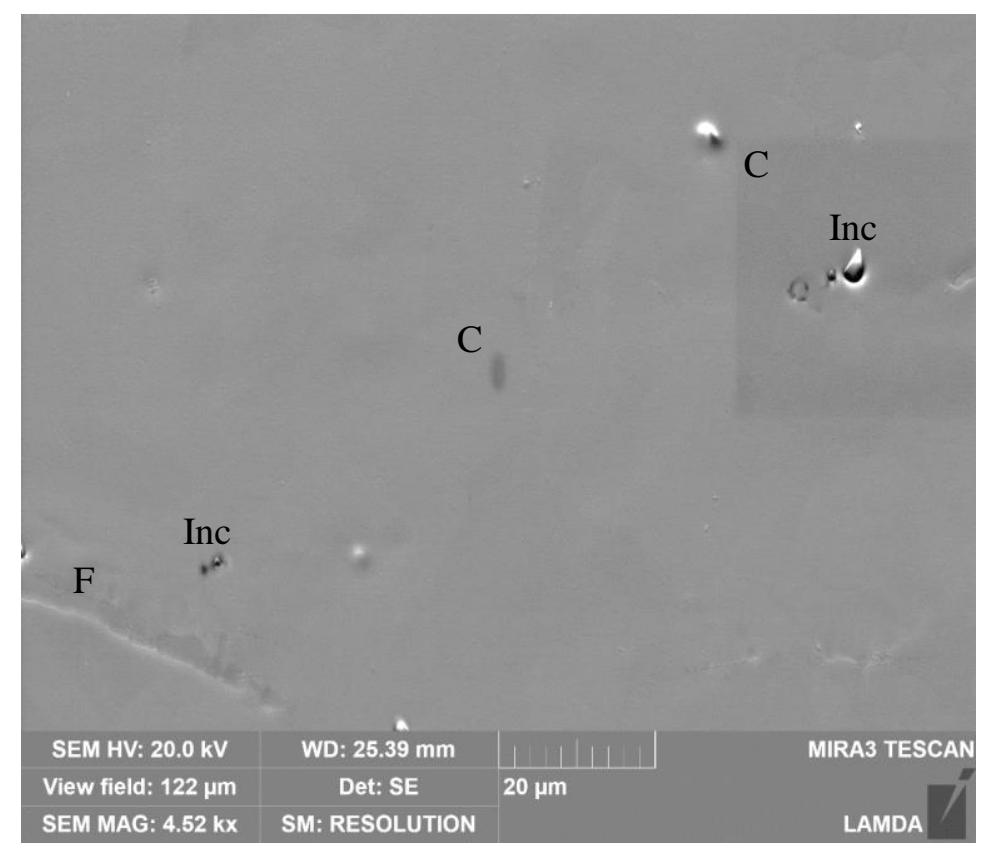

Figure 5. Typical appearance of the electropolished surface (SE detector). One may see few inclusions (Inc), carbon contamination spots $(\mathrm{C})$, and string-like inclusion of ferrite $(\mathrm{F}$, which is visible due to different sensitivity to the $\mathrm{A2}$ electropolishing solution). Note the image is $70^{\circ}$ tilted with tilt correction applied.

After electropolishing, the irradiated miniature specimens exhibited flat, damage-free, and strain-free surfaces with widely spaced inclusions. However, the recorded EBSD patterns (Figure 6) for irradiated steel always appeared to be more blurry, compared to the reference (nonirradiated) material, subjected to the same preparation. The slightly blurry appearance of the Kikuchi lines may be explained by the presence of radiation-induced defects in the lattice. 

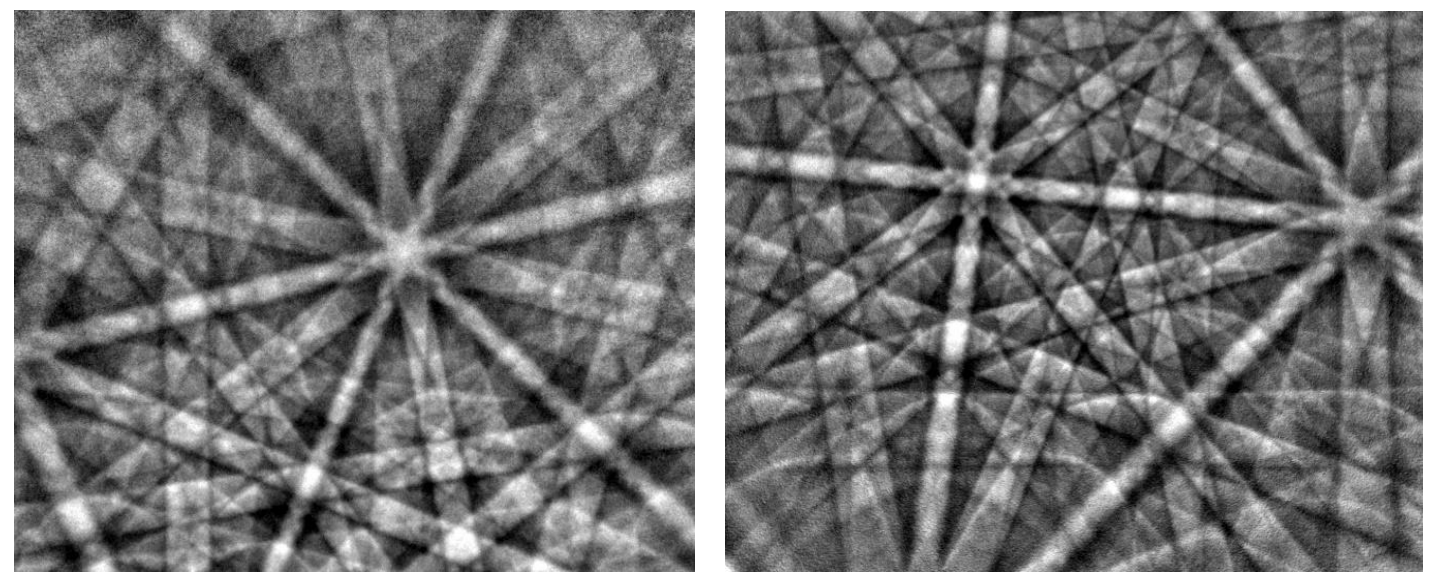

Figure 6. Left: Typical Kikuchi pattern for nondeformed irradiated steel. Right: A pattern for nondeformed reference 304L steel.

\section{MECHANICAL IN SITU TEST TO INVESTIGATE GND EVOLUTION DURING LOADING AND STRAINING}

Within the present project framework, two irradiated and two reference (nonirradiated) specimens were tested in situ; step-by-step loading and deformation mode was employed to collect data for the selected ROIs at multiple stress and strain levels. The HR-EBSD datasets were collected during loading in the elastic mode and at small strains when strain-induced changes in the surface morphology were weak and negligible.

The HR-EBSD tests were interrupted at a plastic strain of $\sim 1-2 \%$; however, the in situ tests, which were continued at moderate and large strain levels, yielded data on the acting deformation mechanisms, misorientation evolution, and lattice rotation (via conventional EBSD scanning). These results will not be discussed in the present report, which focuses solely on the HR-EBSD results.

\subsection{TENSILE CURVES FOR THE TESTED SPECIMENS}

Figure 7 shows tensile curves recorded for the reference (nonirradiated) and irradiated specimens tested in situ, inside SEM. The x-axis represents nominal engineering strain, and the $y$-axis shows engineering stress values. During test interruptions, the load level decreased slightly due to relaxation and creep-like phenomena in the specimens, leading to appearance of the specific force drops on the tensile curves. To minimize creep-like effects, the load was reduced at $\sim 10 \mathrm{~N}$ prior to performing EBSD scans. Ex situ testing with the reference specimen (shown by the smooth curve in Figure 7) yielded the tensile results, very similar to the in situ testing case. Thus, it was assumed that the test interruptions, force drop appearance, and EBSD scans had a weak effect on the further deformation behavior of the material. 


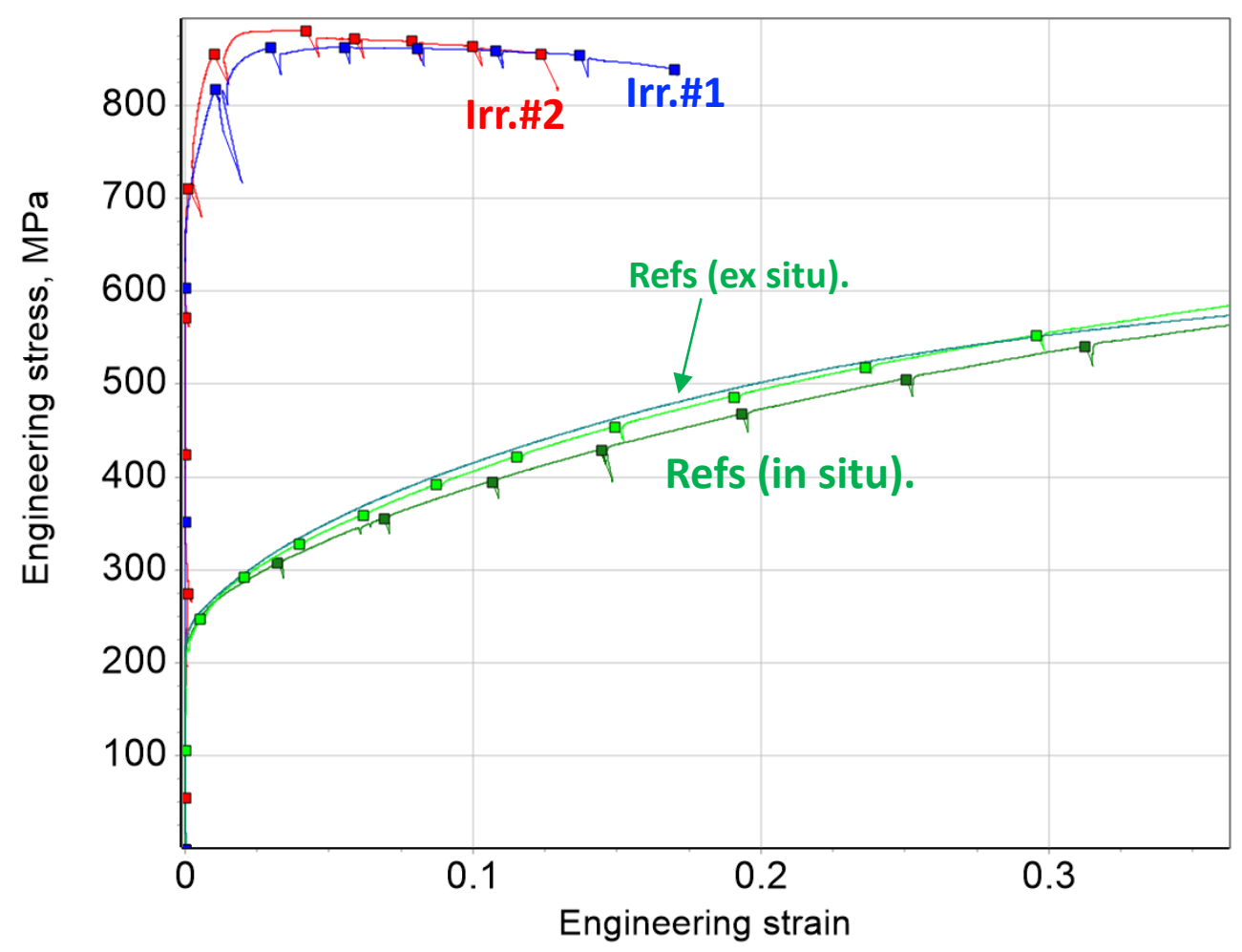

Figure 7. Tensile curves obtained during in situ tests with nonirradiated reference specimens (Refs., green) and irradiated ones (Irr.\#1 and Irr.\#2, blue and red, respectively), damage dose 10.7 dpa. Square symbols show the test interruptions to perform EBSD scans. An example of the ex situ test (the same geometry specimen tested continuously, without interruptions) is also given for comparison.

Two identical SS-Tiny specimens (Figure 3) were tested per condition. This number was considered sufficient, as the results of the tests (i.e., nominal mechanical properties and the appearance of the tensile curves) were close for the nominally identical objects (Figure 7). Testing a larger number of specimens would be beneficial but is not feasible due to the limited time at the instrument (i.e., SEM/EBSD) and expenses associated with irradiated specimen manufacturing and preparation.

As follows from the results, the reference material was an annealed steel with a yield stress (YS 220-240 $\mathrm{MPa}$ ), which is typical for most annealed or hot-rolled 300-series steels. Irradiation at 10.7 dpa led to a pronounced irradiation hardening (YS 750-800 MPa) and ductility decrease, and uniform elongation dropped to $\sim 3-4 \%$. Total elongation is difficult to estimate because the objects were not fractured during the in situ tests. Fracturing irradiated specimens inside SEM is not allowed due to radiological safety rules.

\subsection{SCANNED REFERENCE AREAS}

During the test, several ROIs were selected, tracked, and scanned for each specimen. Due to early necking, irradiated specimens showed strong inhomogeneity in the strain distribution; most of the specimen gauge (outside the neck) showed very low, if any, strain, whereas the neck area revealed high local strain levels. This aspect is discussed in more detail in $[18,19]$. Because of strain localization, one must select and pre-map several ROIs distributed along the gauge, but only one or two ROIs will yield reliable results. 

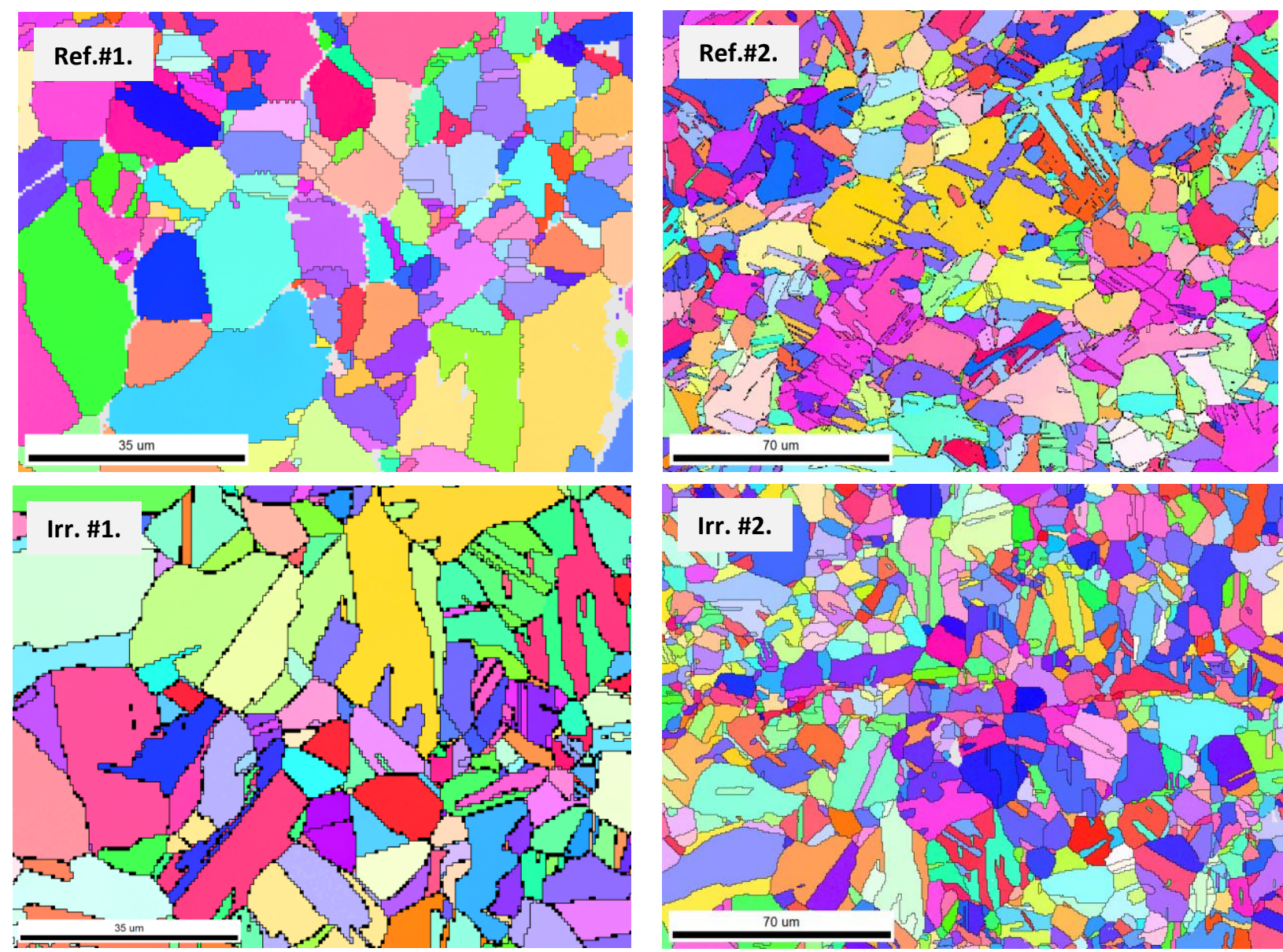

Figure 8. Grain maps (EBSD IPF figures) of typical ROIs for the tested specimens. Note the difference in the magnification and scale for the left and right columns. One may see that grain morphology is close enough between irradiated and reference specimens.

Figure 8 shows typical ROIs for irradiated and reference specimens. For the given material, each ROI contained up to 100-200 grains, thus providing sufficient statistics. In addition, grain orientation distribution was close to random, with very limited if any texturing.

Selecting the ROI is a very important step. First, one must ensure that a sufficient number of grains are present and that grain population represents all basic grain families (e.g., grains oriented close to [001] with respect to the tensile direction). Grain number is easy to estimate using BSE images (Figure 9). Second, the selected area should be free from sediment spots, with a limited number of rough inclusions, defects (e.g., stringers), occasional damage, and scratches. Third, the ROI cannot be too large: ROI increase over some optimal dimensions will increase the total experiment time, as the ROI, as a rule, must be evaluated at each step. 


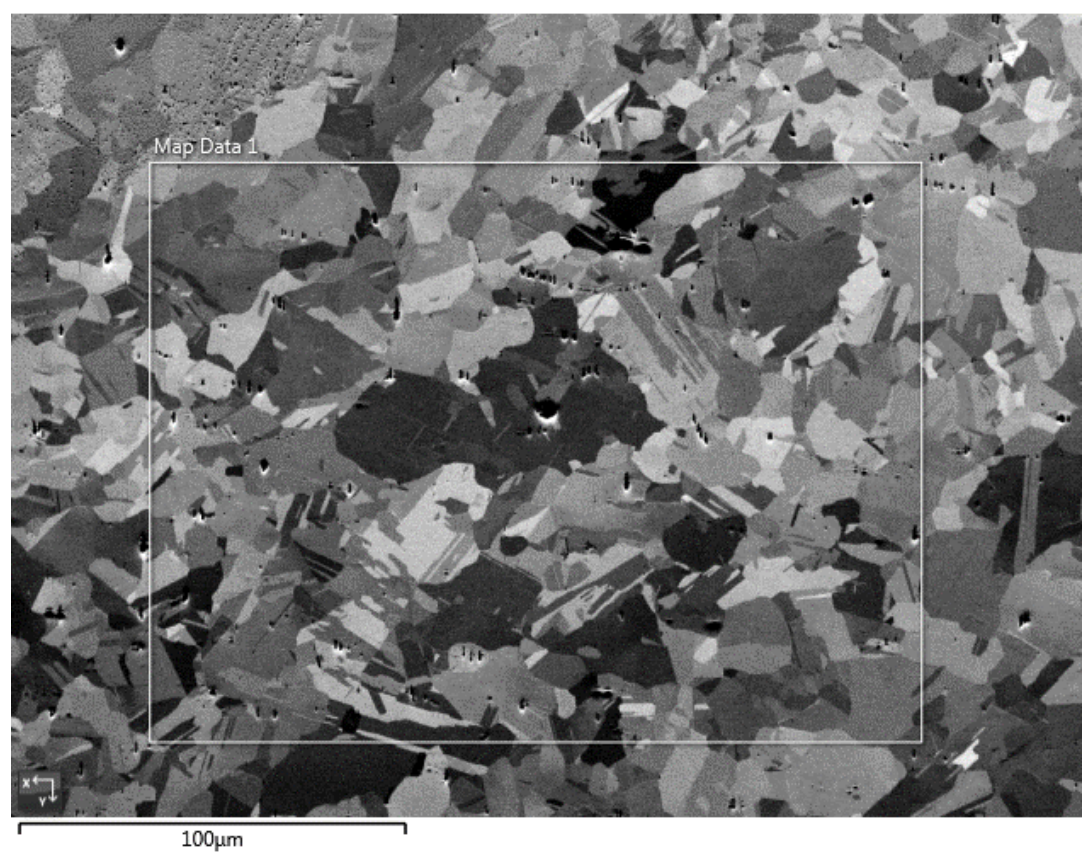

Figure 9. BSE image of a typical ROI (reference specimen). BSE imaging is a convenient tool to evaluate grain morphology and surface quality within the potential ROI.

Of critical importance is maintaining the same SEM parameters during in situ testing. Voltage, beam intensity (current) working distance, magnification, pattern binning, pattern exposure, and background processing settings should be as close as possible for the selected ROI during the test.

\subsection{STEPS OF THE IN SITU TESTS}

The specimens were deformed in the step-by-step mode with multiple steps (up to 8-10 or more) per specimen. Each ROI could be scanned at each step, but this is not always feasible. The number of possible steps and scans is limited by the time available at the instrument; in addition, surface carbon contamination sometimes appears, and a carbon layer may accumulate at the surface, which is detrimental for EBSD pattern quality. To minimize this issue, the number of scans per ROI was limited to $\sim 7-8$.

For irradiated specimens, stress increments were $\sim 150-250 \mathrm{MPa}$ (Figure 10); once a specimen entered the plastic area, displacement control was employed with strain increments of $\sim 0.5-2 \%$. Conventional (relatively fast) EBSD scans were performed in the plastic strain area up to strain level of $\sim 0.2-0.3(\sim 20-$ $30 \%$ ); a fraction of valid points decreases quickly with local strain increase because of surface roughness increase and slip-step evolution. (These data will be discussed later in a separate report.) As a rule, separate ROIs were selected for HR-EBSD and EBSD scans; due to its sensitivity (up to $0.005^{\circ}$ ), the HREBSD is especially beneficial in the elastic strain area and at small plastic strains $(\sim 1-2 \%$ or 0.01 engineering strain). 


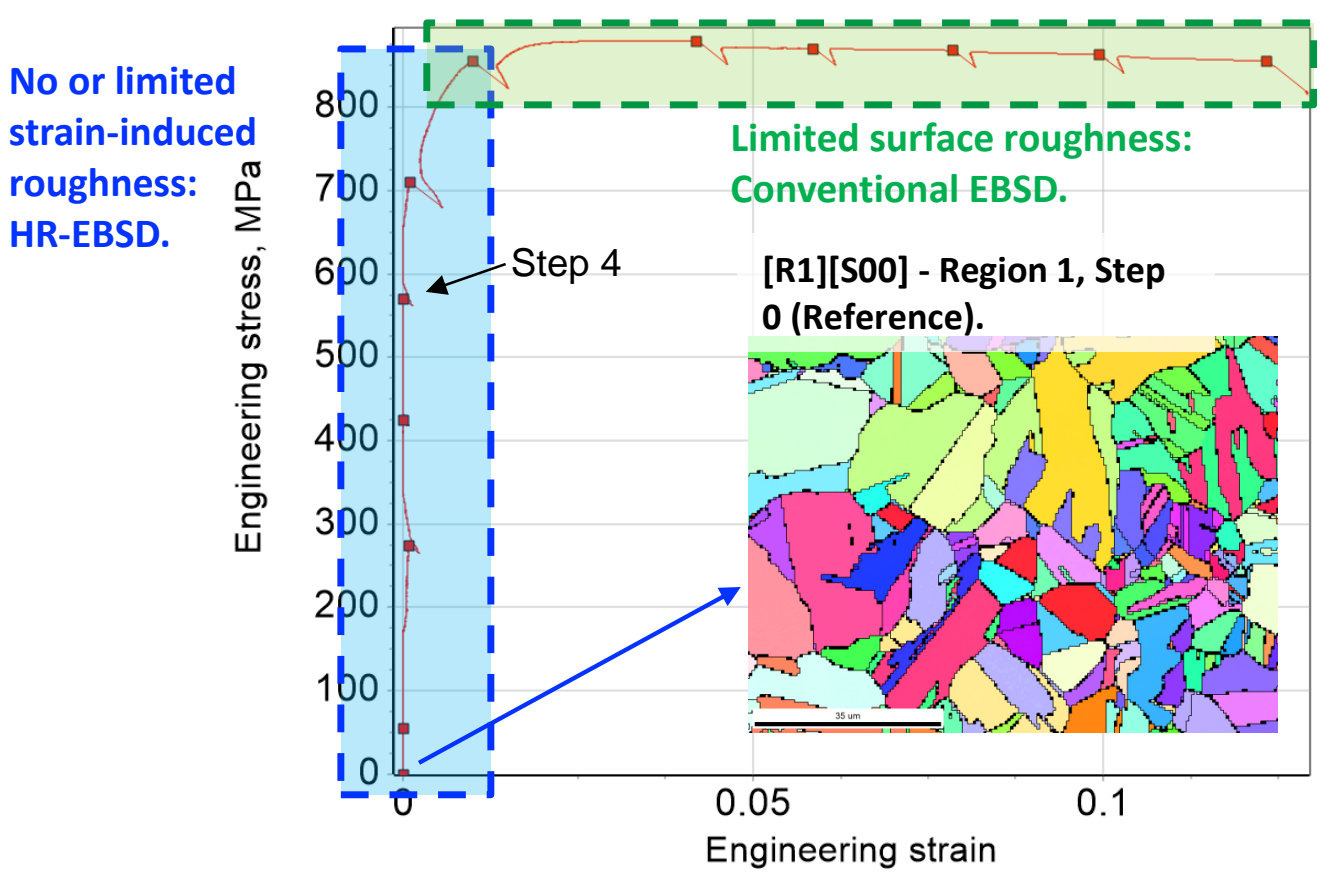

Figure 10. A scheme of a typical in situ test. Square symbols show stops to perform EBSD scanning. Note the same specimen may yield data for a wide range of stresses and strains.

Larger local plastic strains (above $~ 30-40 \%$ ) may be reached easily during in situ testing. Whereas EBSD analysis may be difficult to perform, one may focus on investigating slip line and dislocation channel evolution (Figure 11), as well as on the appearance of strain-induced pores and crack-initiation processes [22]. This possibility was briefly explored but will not be discussed in this report.
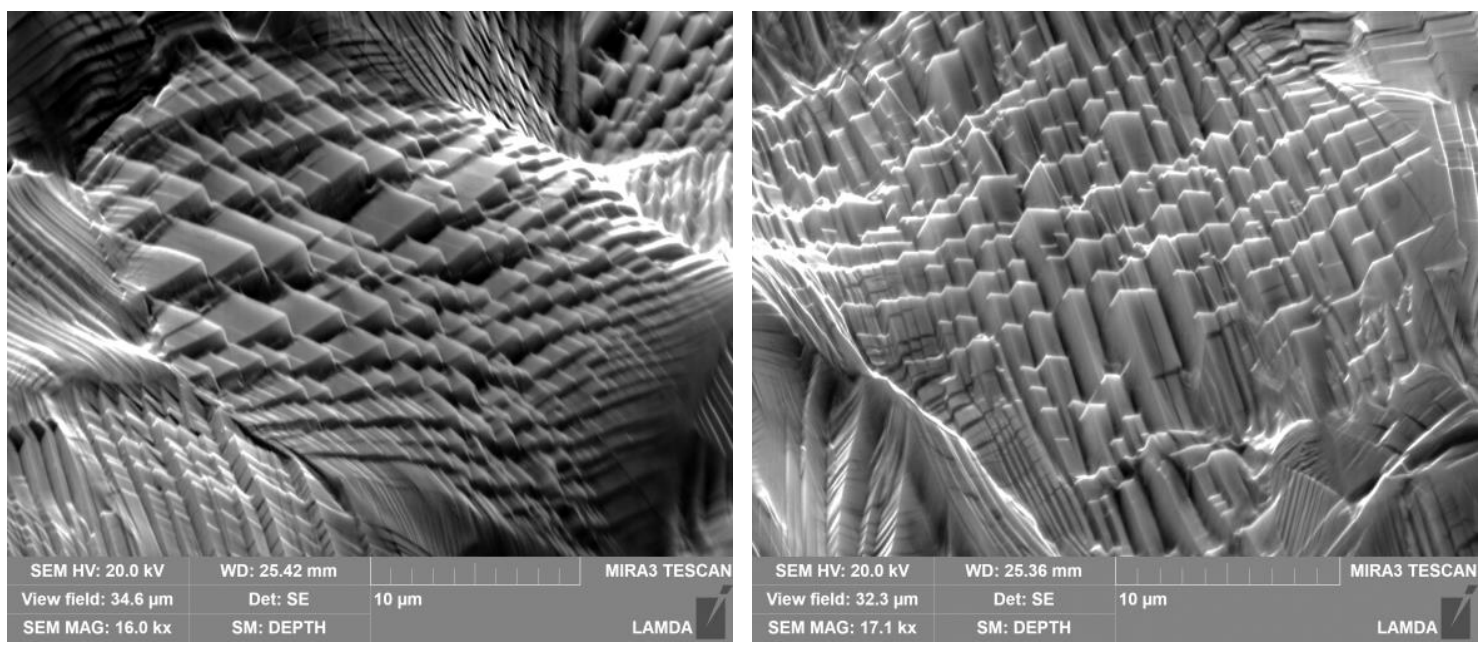

Figure 11. Strain-induced surface morphology in the 10.7 dpa irradiated 304L steel. Despite the interesting appearance, EBSD data interpretation is complicated at such strain levels. Note the images are $70^{\circ}$ tilted with tilt correction applied; high-tilt angle increases the height/depth perception. 


\section{EVOLUTION OF GEOMETRICALLY NECESSARY DISLOCATION: HR-EBSD RESULTS.}

Dislocation field (i.e., density, type, and spatial distribution of dislocations) directly influences the properties and performance of the engineering materials. Whereas microscale (i.e., transmission electron microscopy $[\mathrm{TEM}]$ ) data are abundant, meso-level (i.e., grain scale, group of interacting grains) is comparatively rarely assessed in the literature. This section discusses results related to the GNDs and their density, distribution, and evolution. The GNDs are a subset of dislocations needed to accommodate the misorientation gradients, plastic bending, and rotation in a crystal; they are different from stochastically stored dislocations (SSD), which have equal positive and negative signs and do not contribute to local misorientation gradients. The ratio between GND and SSD depends on material conditions and history and is also sensitive to the EBSD step size and resolution. More information for a number of nonirradiated materials is available in $[11,12,14,15]$.

\subsection{GND Prior Straining}

Small misorientations in the lattice, measured via HR-EBSD, may be converted to a density of GNDs by specialized software (e.g., CrossCourt4), solving Nye tensor [23], or other equations of physics of plasticity. GND calculations were conducted for the acquired datasets to characterize the dislocation density in the irradiated steel.

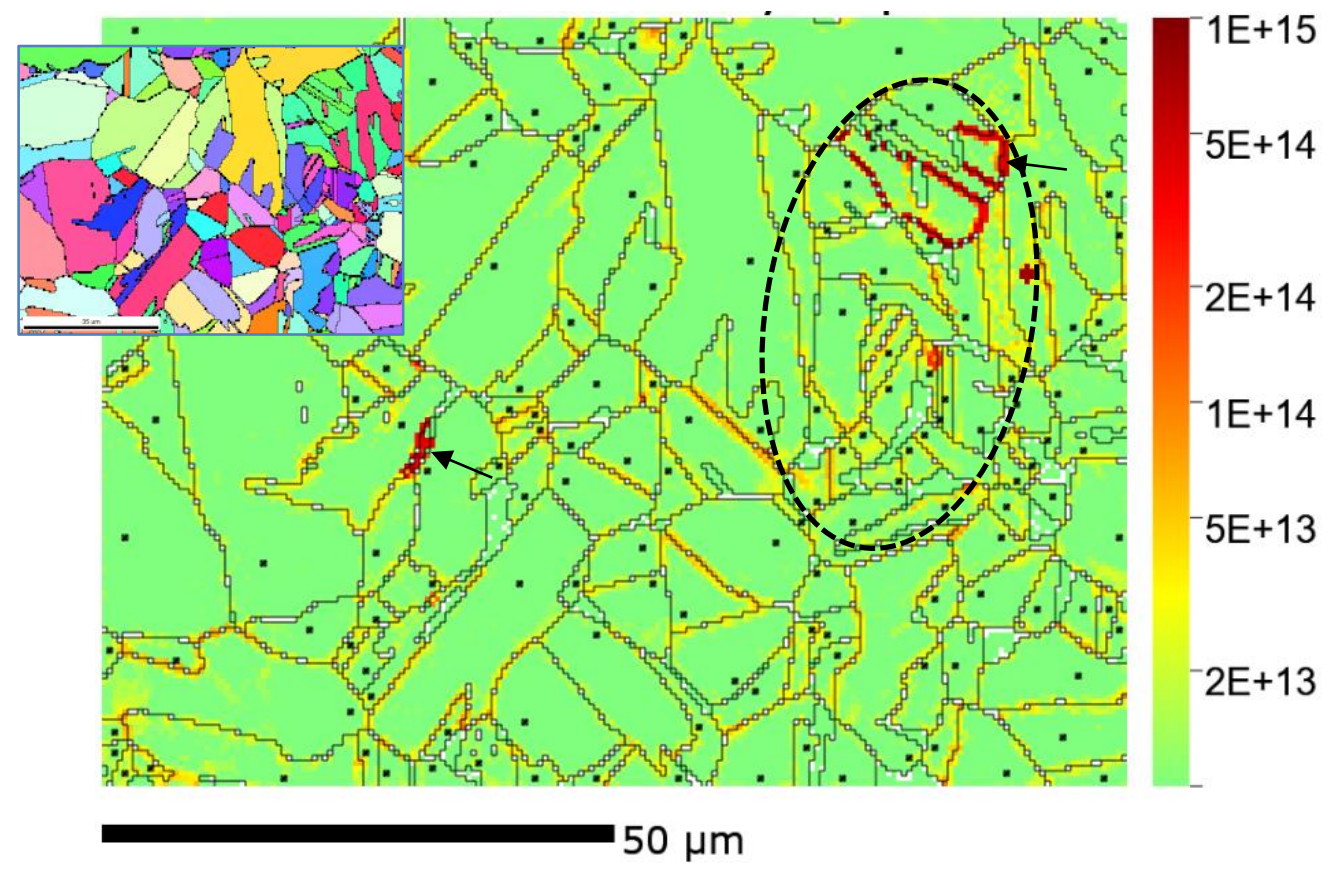

Figure 12. GND map for a typical ROI. Note the logarithmic scale (dimensions: $\mathrm{m}^{-2}$ ). Black arrows mark GBs with high GND density. Dashed oval shows an area with slightly increased GND values in the grain interior and at the GBs.

Figure 12 shows the GND map (i.e., spatial distribution) for the selected ROI of the neutron-irradiated specimen. Because GND varies widely (over $\sim 1.5$ orders of magnitude), the map color scale employs a logarithmic scale. The GND map shows that GND value is low for the grain interior $\left(\sim 10^{13} \mathrm{~m}^{-2}\right.$ or $\sim 10$ dislocations per $1 \mu \mathrm{m}^{2}$ ). Some grains show local spots with slightly increased GND (yellow, $\sim 4 \times 10^{13}$ $\mathrm{m}^{-2}$ ); these areas may reveal the presence of weak shear bands or reflect incomplete recrystallization. Additionally, the GND value often demonstrates an increase along GBs; some GBs may have GND 
values up to $\sim 10^{14}-5 \times 10^{14} \mathrm{~m}^{-2}$. For the given material, grains and GBs with increased GND density appear as local spots or specific clusters (Figure 12). As expected, GND distribution reflects material processing and recrystallization behavior, superposed with possible deformation and straining while under irradiation or in service. These aspects, practically not described in the literature, should receive more attention. In the present work, it was important to confirm that the HR-EBSD approach provides reasonable GND values and can detect and quantify variations across the structure.

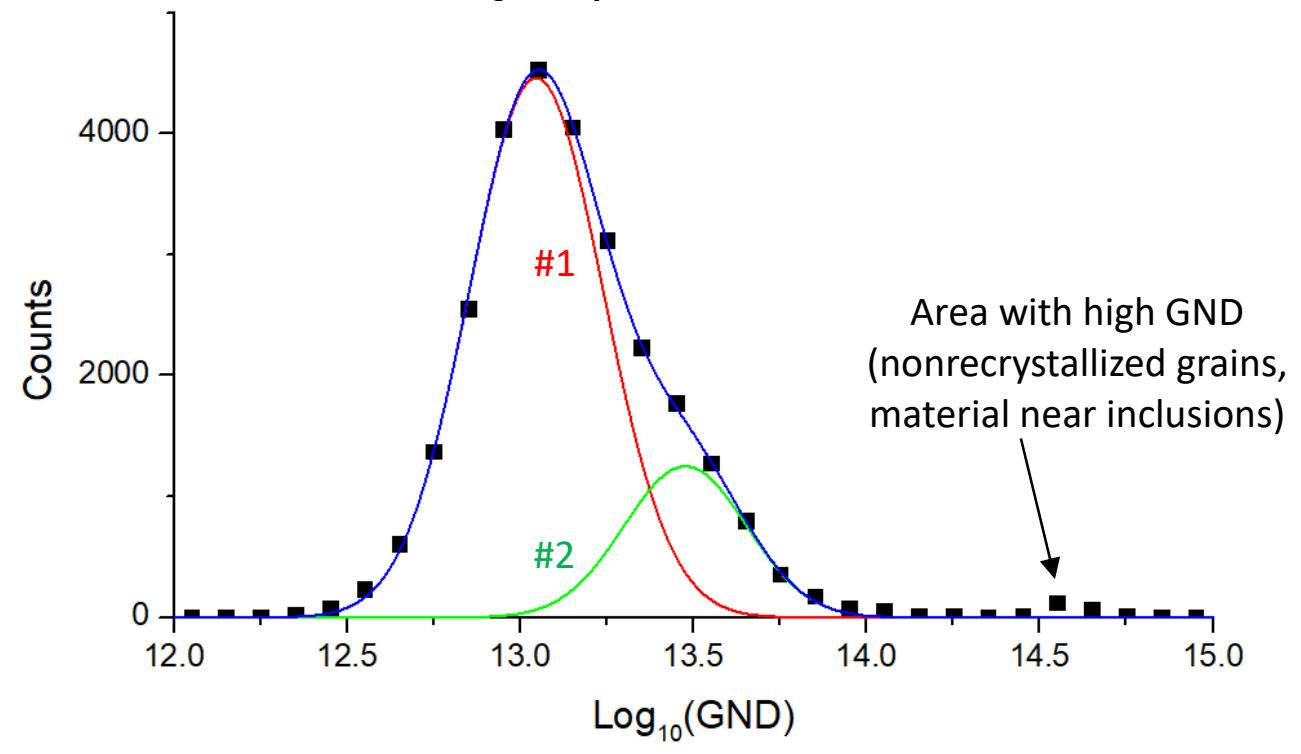

Figure 13. Histogram of GND density distribution, presented using the logarithm scale, in the specimen prior to straining. The GND distribution may be described by two Gauss-like functions (labeled as \#1 and \#2), corresponding to the different types of dislocation substructures (e.g., chaotic distribution of dislocations and dislocation walls).

Figure 13 shows the histogram of GND distribution for the area, depicted in Figure 12. The analysis revealed that the GND histogram has a log-normal distribution (i.e., having Gauss-like bell shape, but in the semilogarithmic coordinates), and the acceptable fitting degree may be reached using two bell-like functions. Log-normal distribution describes most of the data; however, a few small "hot spots" with increased GND density appear at the right side as a very small additional peak.

The reasons for the log-normal distribution of GND density are not clear at this time. Similar trends (e.g., log-normal distribution) were observed for crystal lattice misorientations measured via conventional EBSD and for spacing between individual dislocations, measured via TEM [24]. Distributions, similar to the log-normal curves, often exist for radiation-induced defects such as Frank loops.

Another interesting feature is the presence of two overlapping Gauss-like curves (Figure 12). One could speculate that the curves correspond to different types of dislocation structures; for instance, one of the curves may reflect a random or chaotic dislocation distribution, whereas another may be related to the appearance of dislocation arrays, walls, or low-angle boundaries. This question requires additional work, and HR-EBSD data for the selected area or grain should be compared to the TEM results via targeted loftout. 


\subsection{SPATIAL GND EVOLUTION DURING THE TEST}

Figure 14 shows the average GND density for the selected ROI. One may see that changes in GND density are relatively weak below $\sim 550 \mathrm{MPa}$ (step 4 and below) and that GND density growths linearly with plastic strain increase.
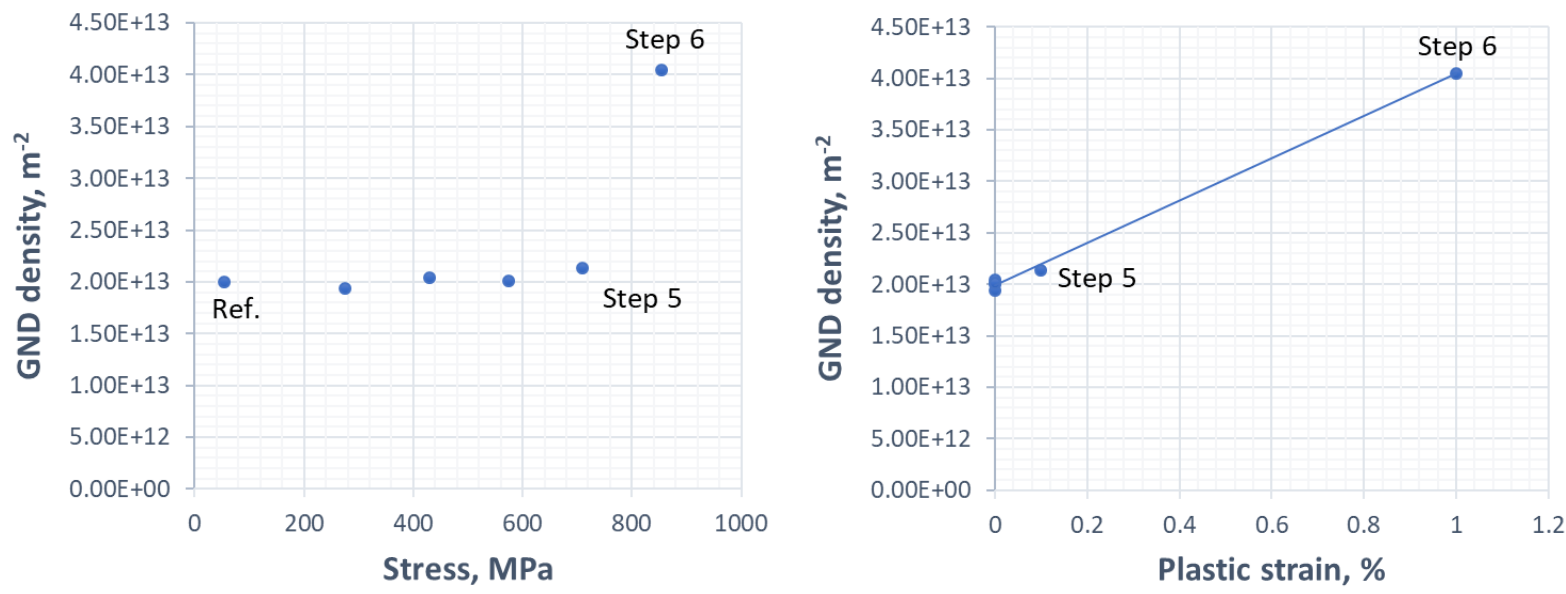

Figure 14. Average GND density for the ROI, shown in Figure 15, as a function of stress and plastic strain.
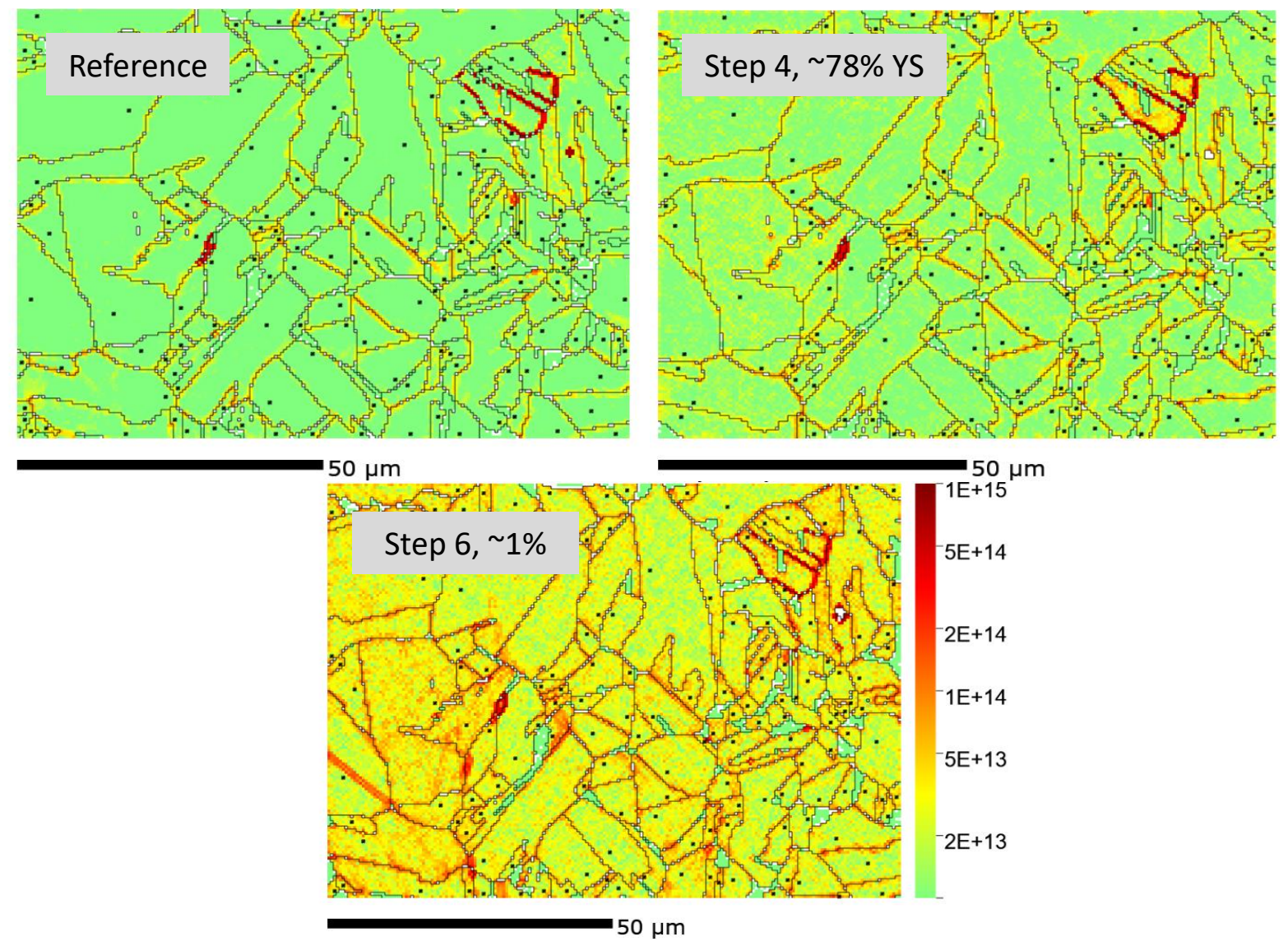

Figure 15. Spatial GND evolution inside a typical ROI during in situ testing. The scale is the same for all maps within the figure. 
Figure 15 shows GND maps for the same area at different steps of the in situ tests. Changes in the GND density, even being small in absolute numbers, become clearly visible in the GND maps at $\sim 0.78$ of YS (step 4, Figure 10). GND maps for the previous steps are not shown because changes were much weaker compared to step 4. At step 4, the grain interior shows some increase in the GND values, and many GBs reveal increased GND as well. It is important to emphasize that many grains do not show obvious slip lines or defect-free channels at this step. A 1\% strain (step 6) showed pronounced GND density growth inside the grain body and appearance of multiple hot spots at many locations; GND density strongly increased near some GBs.

\subsection{EVOLUTION OF STATISTICAL GND DISTRIBUTION}

Figure 16 shows the histogram of GND distribution at different steps of the in situ test for the area, showed in Figure 13 and Figure 15. With increased stress and strain, the GND histogram keeps its initial shape (i.e., superposition of two Gauss-like curves, Figure 13) but shifts at the right, reflecting GND density growth. Changes in step 2 are small but nevertheless are visible. Step 5 shows clear changes, and $1 \%$ strain (step 6) reveals increased GND at approximately half the order of magnitude. Note that all scans, performed at different steps, revealed a small local increase at X 14.6, corresponding to the hot spots, local areas with increased GND density (Figure 15).

Interestingly, the HR-EBSD approach detects changes at stresses below formal yield stress (e.g., step 5 with a load level of $\sim 710 \mathrm{MPa}$ ). It means that, if a material experiences overloading or fatigue while in service, the HR-EBSD analysis may be able to quantify the defect structure and reveal changes, compared to the reference conditions.

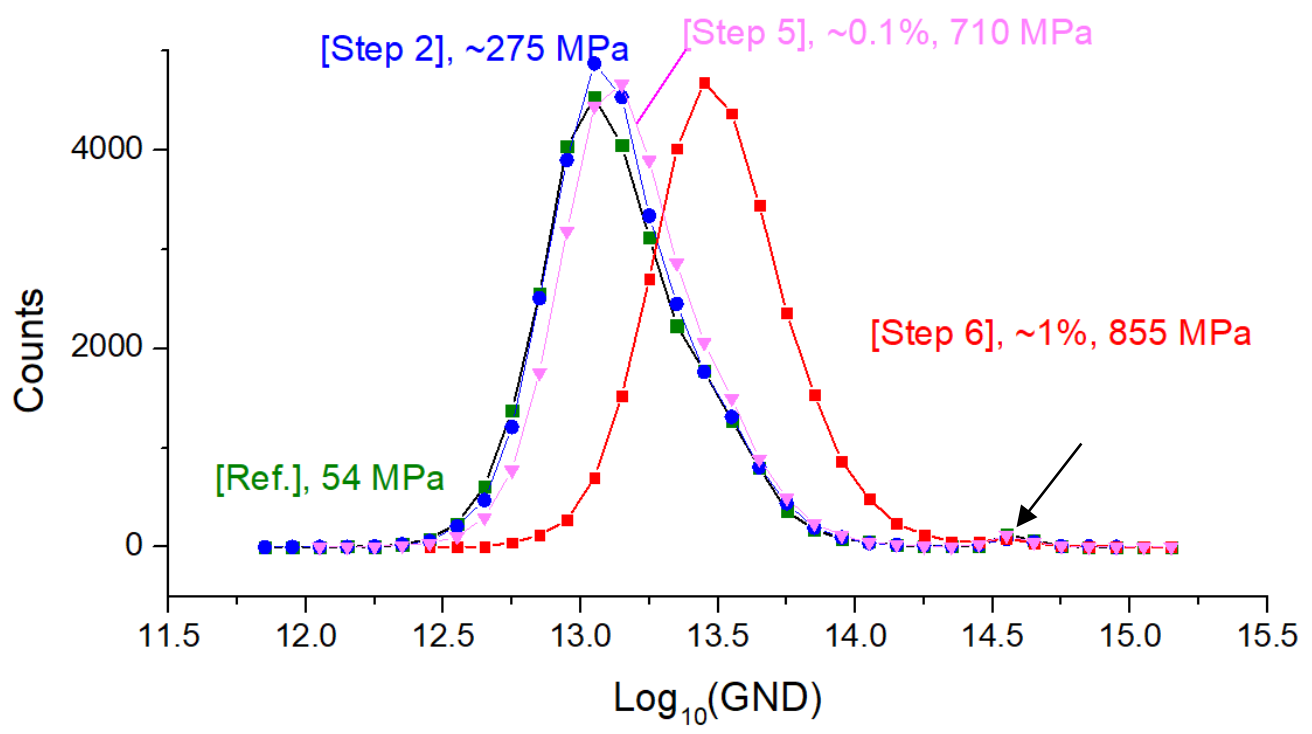

Figure 16. Histogram of GND density at different steps of the in situ test (see the tensile curve in Figure 10). Black arrow indicates a weak increased local GND associated with hot spots; its location [ $\log _{10}(G N D)$ 14.6] and amplitude were close for the analyzed stress/strain range.

Further data analysis is in progress, to investigate GND evolution in the dislocation channel vicinity, near GBs and triple junction points. 


\section{STUDYING CHANNEL-GRAIN BOUNDARY INTERACTION VIA HR-EBSD ANALYSIS}

Dislocation channel-GB interaction points may be of special interest to the present work. The appearance of dislocation pileup may lead to formation of a spot with high local stresses and, in turn, to crack initiation in the corrosion environment $[16,17]$. Strain/stress localization caused by dislocation channeling is assumed to be a key factor, influencing stress corrosion cracking [16]. Stress amplitude, as well as local stress state, should depend on the GB orientation with respect to the externally applied stress direction on GB type (e.g., random high angle boundary or special $\Sigma$-type boundary), relative orientation of the interacting grains, and many other factors [25].

At the moment, HR-EBSD is the only tool available at the lab scale to investigate internal stresses at the grain level [11,12]. A few papers have been published on ex situ analysis of deformed irradiated steels $[16,17]$, but very limited, if any, data are available on in situ testing. The subsections below will discuss a few particular cases of the channel-GB interaction. The HR-EBSD scans were performed within the area, shown in Figure 12 and Figure 15 after step 6 (plastic strain of 1\%).

\subsection{CASE \#1}

At the small plastic strain level, the specimen surface is still flat enough, and strain-induced roughness may be neglected. The number of strain-induced features (i.e., channels) and their density are also limited, allowing for studying specific events in detail.

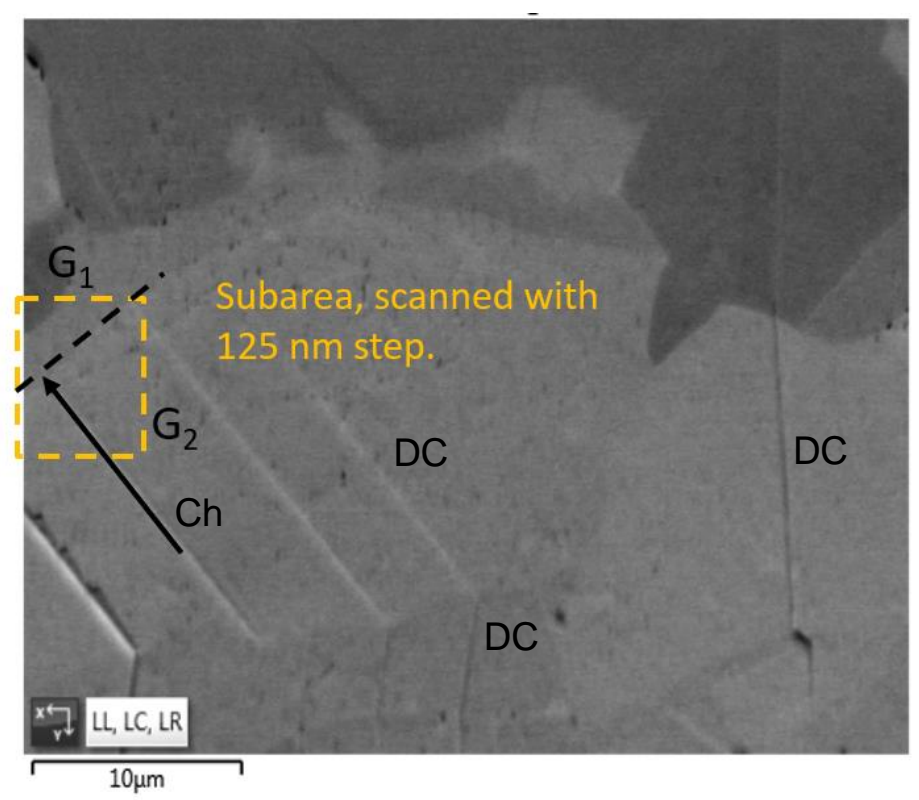

Figure 17. Location \#1. DC: dislocation channels. $G_{1}, G_{2}$ : grains within the subarea scan; $C h$ : channel hitting the boundary between $G_{1}$ and $G_{2}$. Dashed rectangle approximately shows the subarea scanned with $125 \mathrm{~nm}$ step.

Figure 17 shows a subarea - part of the ROI, scanned at a high SEM magnification and with a smaller EBSD step size - that has few grains $\left(\mathrm{G}_{1}, \mathrm{G}_{2}\right)$ and only one channel. (Note $\mathrm{G}_{2}$ has several channels, but only one is visible in the subarea.) Grains and GBs are visible in the different areas due to orientation contrast and BSE detector usage. Defect-free channels appear as a sharp straight line within the grains. Two basic channel-GB interaction mechanisms may exist [16]: the channel may penetrate the GB (e.g., 
channels marked as DC in Figure 17) or may be arrested at the GB (e.g., channel marked as Ch in Figure 17). As expected, channel penetration should not lead to a significant increase in the stress level [16], whereas channel arrest and dislocation pileup may result in elevated stresses [1,2,16]. At this particular location (Figure 18), the channel (Ch) "hits" a $45^{\circ}$-inclined GB, and no GB penetration was observed (i.e., this channel is an arrested or discontinued channel, in the terms of [16]). Conventional EBSD showed only a minor $\sim 0.5^{\circ}$ increase in misorientation in both grains.

Note that the real GB orientation is not known; focused-ion beam milling or mechanical polishing and subsequent EBSD scanning are required to retrieve full GB plane information.
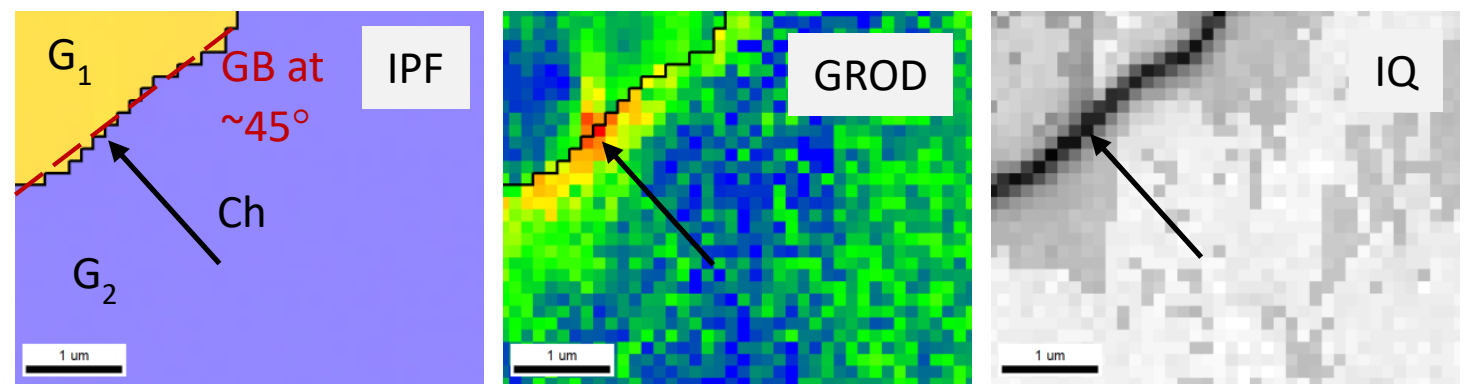

Figure 18. EBSD maps for the subarea, shown in Figure 17.

Figure 19 shows HR-EBSD maps for the same location: normal stresses in all three directions (with $\sigma_{33}-$ stress normal to the surface - being zero) and shear stresses. It is important to underline $[10,12,14]$ that stresses are given with respect to some selected point within the grain (reference point marked by X's in the Figure panels); HR-EBSD currently is unable to measure absolute stresses or absolute elastic strains [10]. Nevertheless, the in-grain distribution may be analyzed with good spatial distribution.

As follows from the results, the peak $\sigma_{11}$ stress at the channel-GB interaction point reached $\sim 1.2-1.4 \mathrm{GPa}$; this in-grain stress increment does not include global external stress value ( $\sim 800 \mathrm{MPa})$. The $\sigma_{22}$ stress also was sufficiently high at $\sim 1.2-1.3 \mathrm{GPa}$. Increased $\sigma_{11}$ was observed in both grains, whereas a $\sigma_{22}$ value jump was observed only in $\mathrm{G}_{2}$. Additionally, increased $\sigma_{11}$ has strong spatial localization: it presents only above the $\mathrm{Ch}-\mathrm{GB}$ interaction location. Shear stresses (i.e., $\sigma_{11}, \sigma_{31}, \sigma_{23}$ ) also have complex distribution and change the sign near the $\mathrm{Ch}-\mathrm{GB}$ interaction point. 

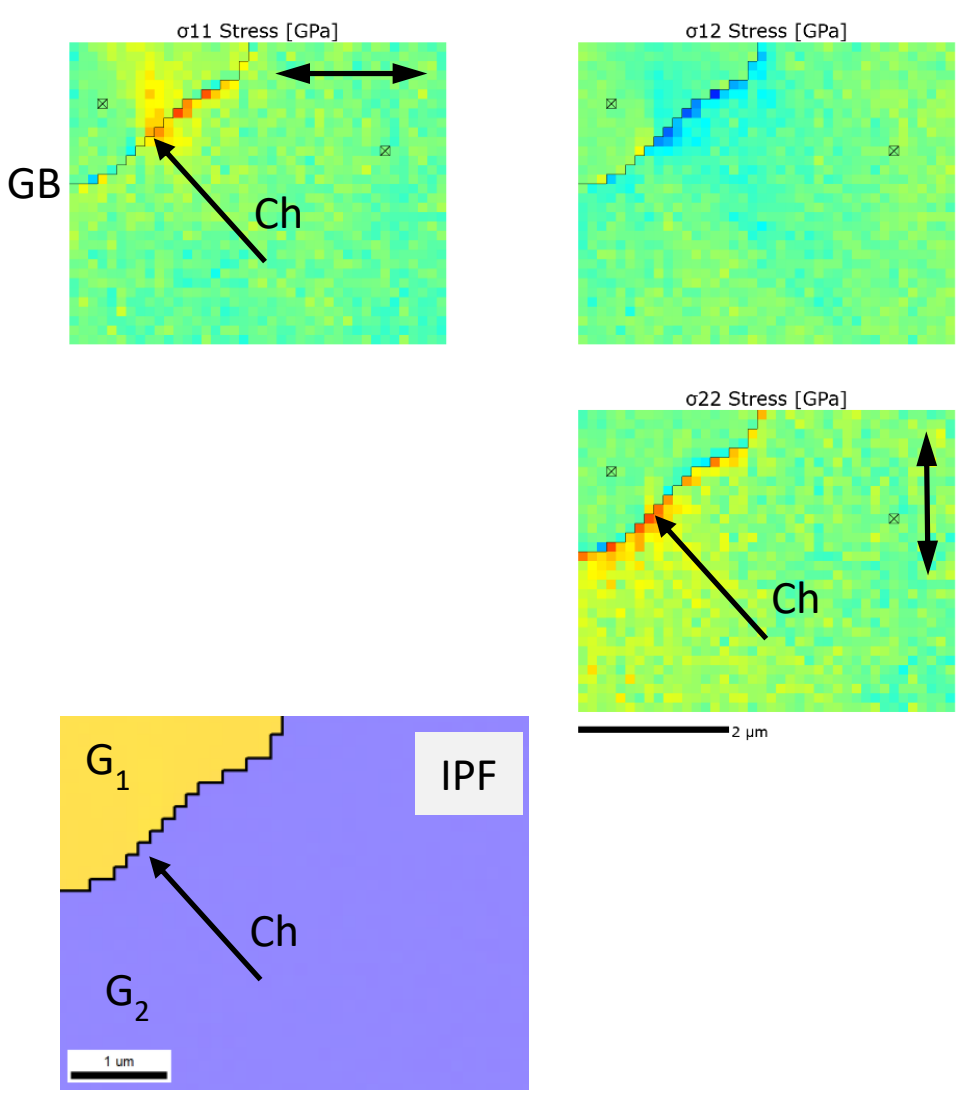

Figure 19. HR-EBSD maps for the channel (Ch)-grain boundary (GB) interaction (location \#1, also see Figure 17 and Figure 18). $\sigma_{11}$ shows stress in the tensile direction (horizontal).

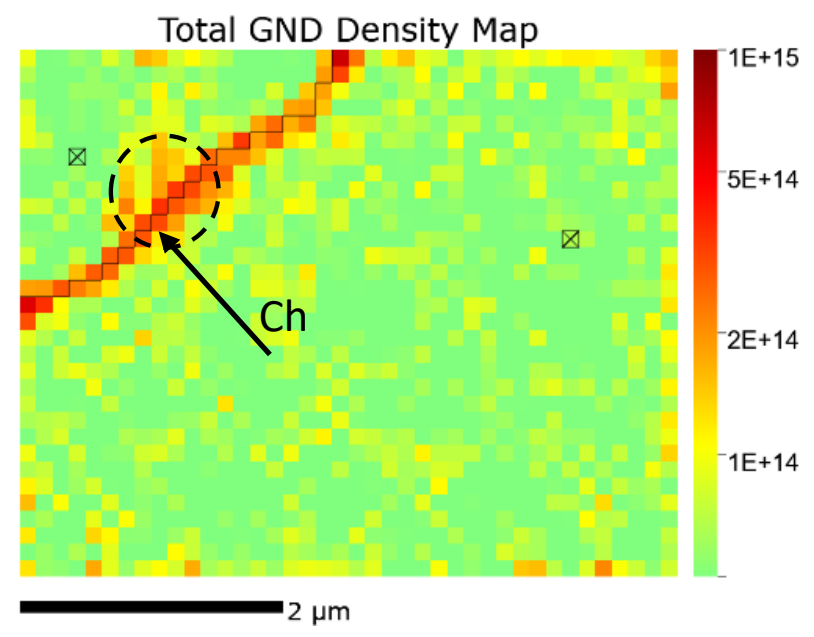

Figure 20. GND map for location \#1. Note this map has a $125 \mathrm{~nm}$ step size, so it cannot be directly compared with Figure 15, which has a different EBSD step size.

Figure 20 demonstrates the GND map for the subarea shown in Figure 18 and Figure 19. Note that the channel is not visible in $\mathrm{G}_{2}$ in the GND map, suggesting a very low number of retained dislocations inside the channel in the bulk grain. The channel-GB interaction location also shows very weak GND increase in $\mathrm{G}_{2}$; however, $\mathrm{G}_{1}$ reveals obvious GND growth. The local $\sim 0.5 \mu \mathrm{m}$ area in $\mathrm{G}_{2}$ has larger GND values, 
compared to the surrounding volume. It may suggest the presence of dislocation pileup as well as some plastic strain in the target $\mathrm{G}_{1}$ grain, most likely, caused by relaxation of peak stresses near the channelGB interaction point. This GND growth did not result in the formation of the defect-free channels in the target grain (Figure 17); it can be speculated that channels in the target grain $\left(\mathrm{G}_{2}\right)$ may appear later if deformation progresses.

Figure 21 compares the spatial (map) and statistical distribution of stresses (here: $\sigma_{11}$, the stress in the tensile direction) at this particular location. In the map, one may see a hot spot, a stress increase resulting from the channel-GB interaction, whereas the rest of the map appears to be uniform. The same dataset, being plotted as histograms (separate for each grain), reveal near-normal distribution. The maximum of the bell-like function is slightly shifted with respect to the zero stress value, depending on the reference point selection.
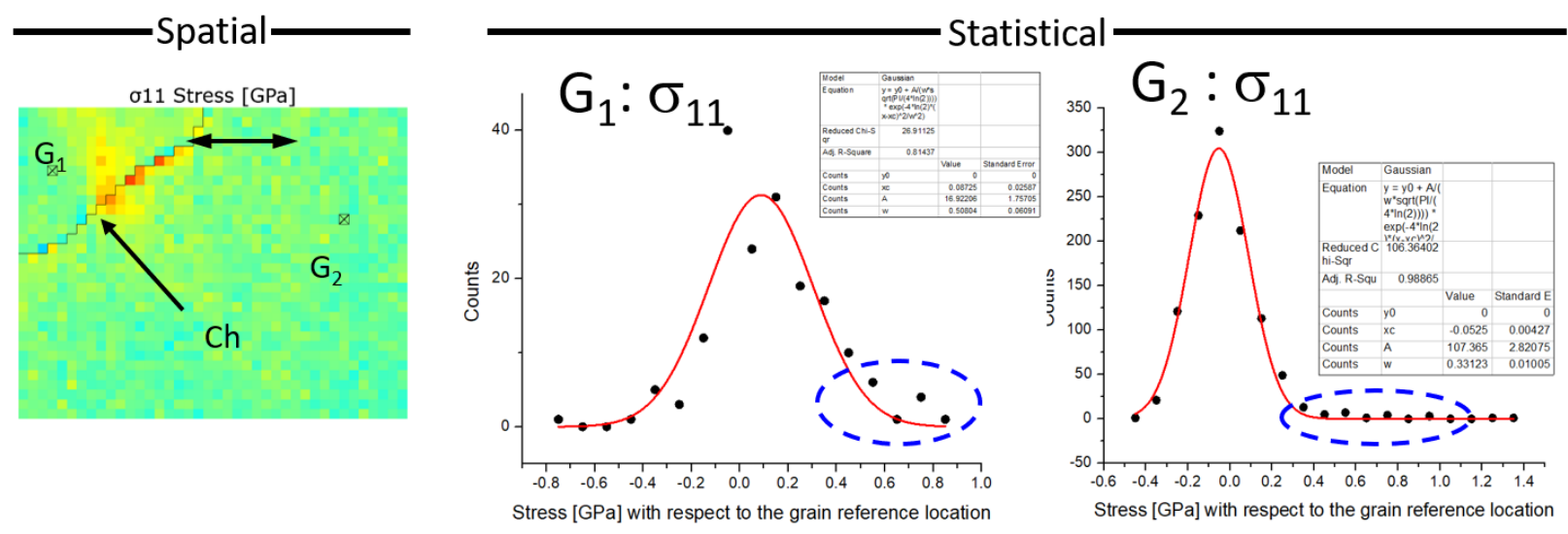

Figure 21. Spatial vs. statistical distribution of the stress values.

The stress distribution map (for the $\sigma_{11}$ stress value) shows more or less uniform stress fields in G1 and G2 with a hot spot connected to the GB-channel interaction.

In the first iteration, the in-grain stress distribution ( $\sigma_{11}$ stress in this example) may be described by a Gauss-like function. The larger the grain, the more close fitting may be achieved. The presence of stress hot spot(s) may appear as a Gauss bell distortion (if the grain is small or a small grain portion is scanned, such as G1) or weak, minor variations of the "tails" in the high strain area.

\subsection{CASE \#2}

In this case, the dislocation channel (Ch) hits the GB at an angle of $\sim 15^{\circ}$ with respect to the tensile axis. Such a configuration, according to $[6,16,17]$, is not favorable for crack initiation; nevertheless, stress/strain and GND fields are of interest. Figure 22 shows the EBSD dataset for the selected subarea. One may see the channel $(\mathrm{Ch})$ in $\mathrm{G}_{2}$, hitting the $\mathrm{G}_{1}-\mathrm{G}_{2} \mathrm{~GB}$. Only one phase presents in the field of view (i.e., fcc); see the phase index map in Figure 22. The Kernel average misorientation (KAM) map reveals strong local misorientation inside the channel, as well as at the channel-GB interaction points. 

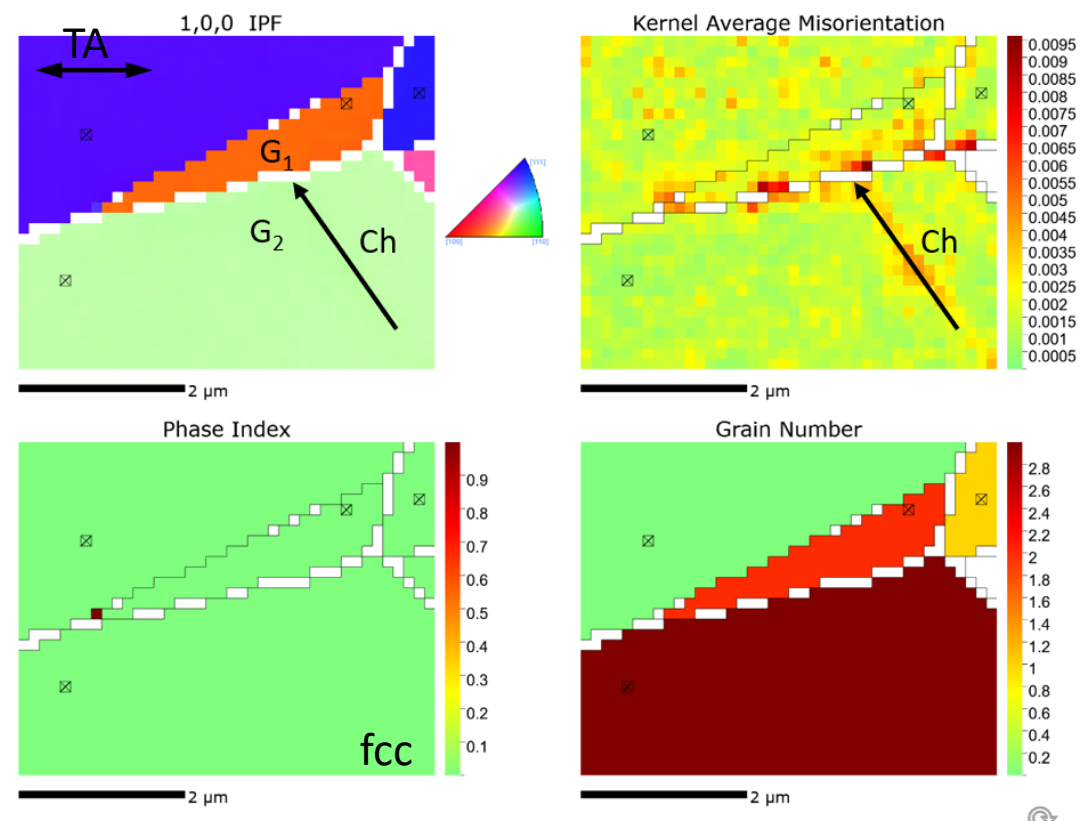

Figure 22. EBSD dataset for the case \#2. TA: tensile axis. A few points located close to GBs were not indexed properly due to the partial pattern overlapping.
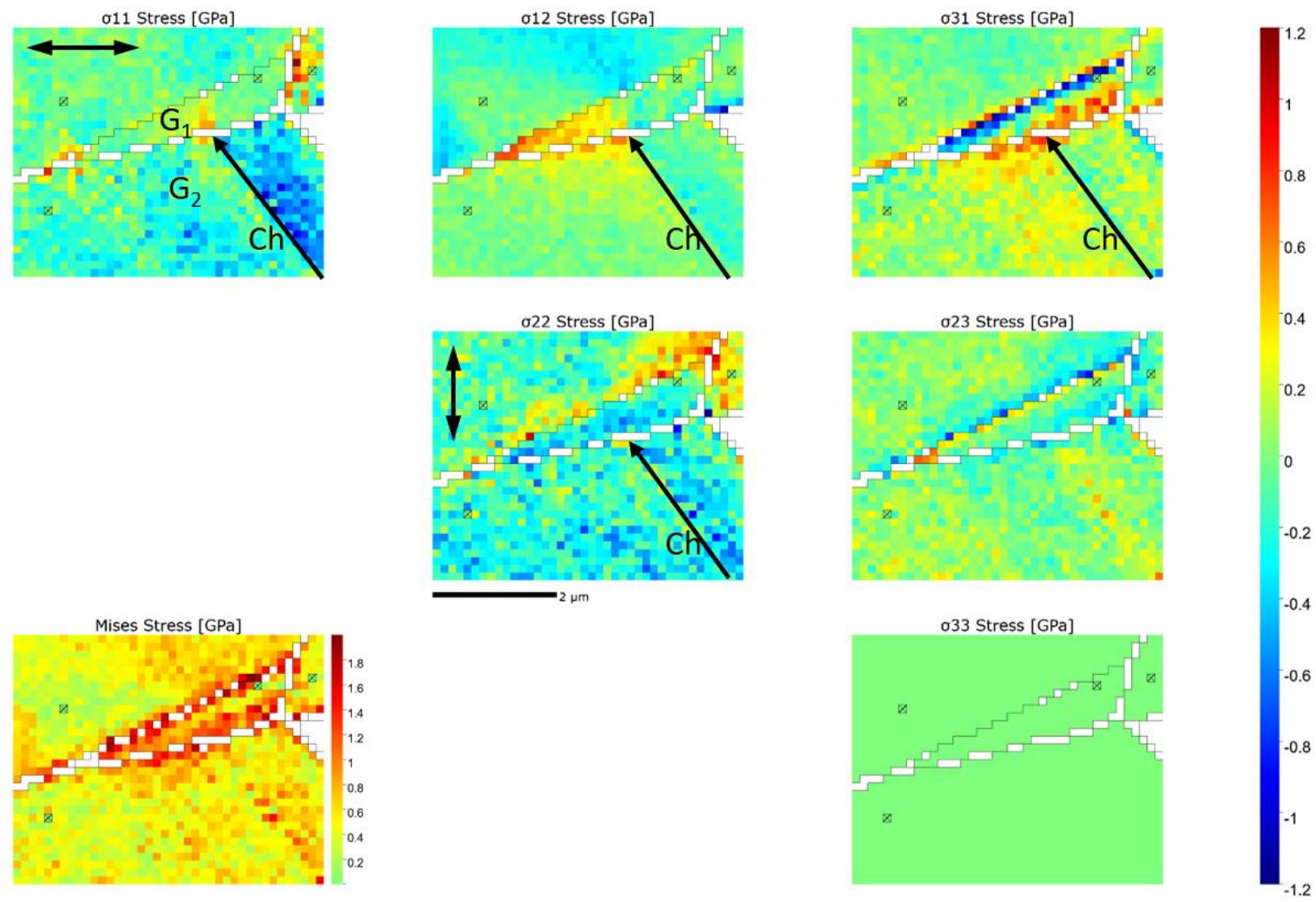

Figure 23. HR-EBSD dataset (elastic stresses, calculated by CrossCourt4 software) for case \#2. The tensile direction is horizontal. 
Figure 23 shows the HR-EBSD dataset for the selected location; recording and processing the Kikuchi patterns allowed for calculating stress values inside the grains. One may see an increase in the $\sigma_{11}$ value at the channel-GB interaction location. The presence of the channel $(\mathrm{Ch})$ generates increased tensile stress level, $0.5 \mathrm{GPa})$, in the target grain $\left(\mathrm{G}_{1}\right)$. At the same time, $\sigma_{11}$ local stress decreased in $\mathrm{G}_{2}$ along the channel line. The presence of the channel redistributed the in-grain stresses. One may speculate that the channel is a layer of a soft, easily deformed material between two grain halves. The halves slip or rotate along the layer plane, by analogy with [1,2].

The $\sigma_{22}$ value (stress, normal to the tensile direction) shows no tension and even has a tendency to experience some compression in $\mathrm{G}_{1}$ and $\mathrm{G}_{2}$. An integral stress parameter (i.e., von Mises stress value) reveals elevated local stresses at the GB, but no obvious stress increase presents at the channel-GB interaction point.

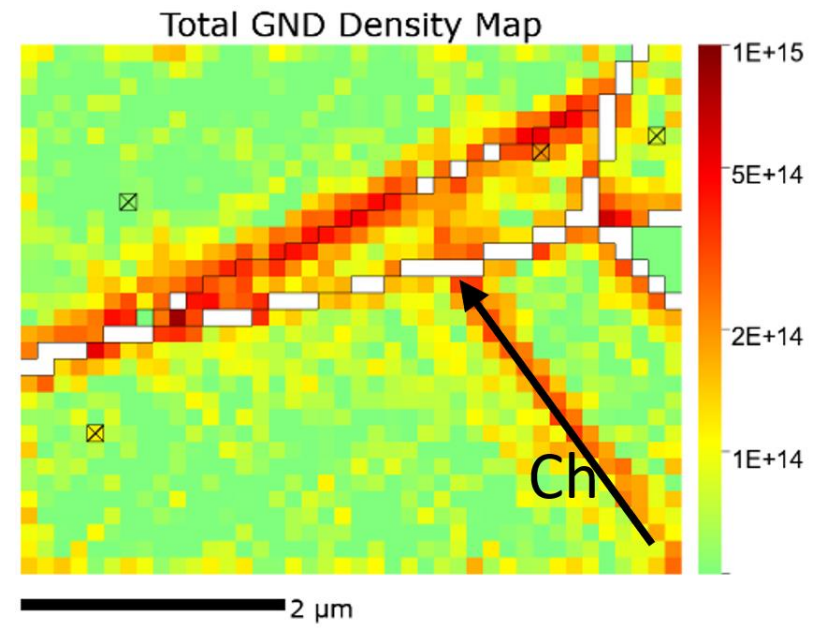

Figure 24. GND map for the area shown in Figure 22 and Figure 23.

Figure 24 demonstrates the GND map for the same area. One may see an increased GND density along some GBs, and, unexpectedly, also relatively high GND values inside the channel (Ch). In contrast to case \#1 (Figure 20, channel without GND increase), the present channel contains a significant number of GNDs. It points to the complex character of processes inside defect-free channels, most likely not only shear but also some relative rotation of the grain portions, "bisected" by the channel.

\subsection{CASE \#3}

In this case (Figure 25), the channel hits the GB, inclined at $\sim 90^{\circ}$ (i.e., near-normal angle) with respect to the tensile axis. The channel-GB interaction results in penetration (in terms of $[6,16])$ : intense plastic deformation occurs in the target grain, $\mathrm{G}_{1}$. The penetration generates dislocation "bursts" and strong misorientation variations in $\mathrm{G}_{1}$. These misorientations are easy to see in the grain reference orientation deviation (GROD) map (Figure 25, right) and also in the IPF map as a change in color. According to the GROD map, local in-grain misorientation may reach $\sim 10^{\circ}$, and misorientation gradients may be as high as $\sim 10-20^{\circ}$ per $1 \mu \mathrm{m}$. 

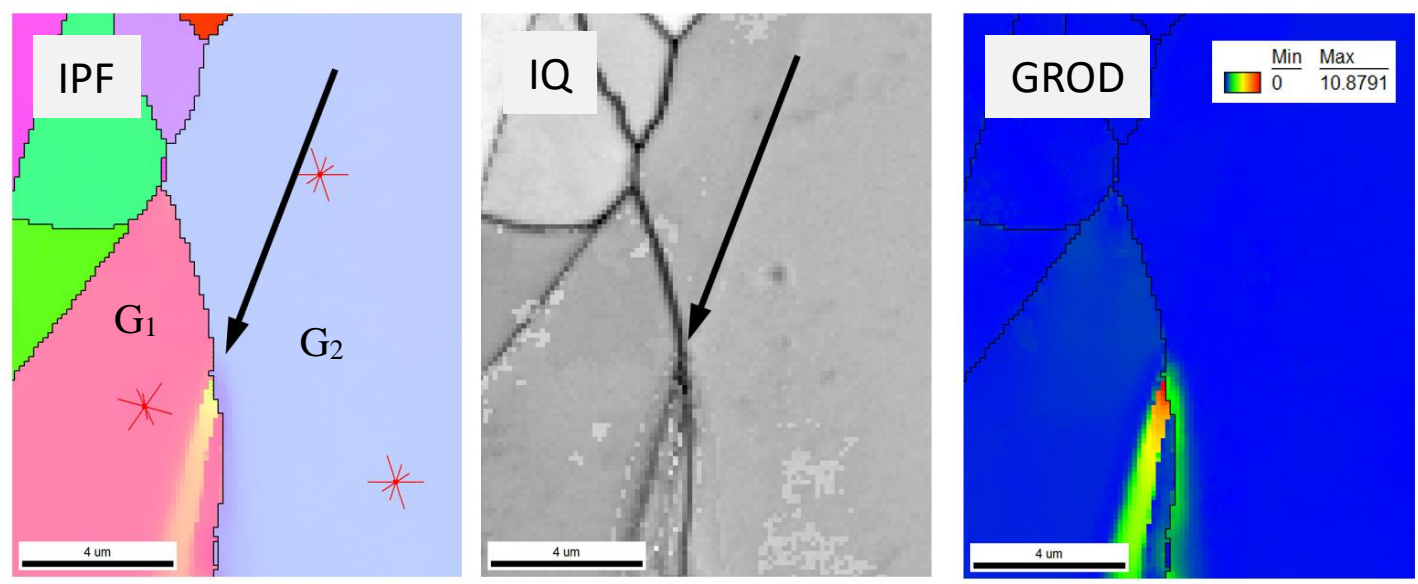

Figure 25. Conventional EBSD maps showing IPF, IQ, and GROD map for the Case \#3 location.

Unfortunately, the HR-EBSD software failed to fully process this dataset, and the channel-GB interaction area generated no reliable outcome. The analysis revealed an unexpected issue: strong local degradation of Kikuchi patterns. Figure 26 shows the reference pattern (\#9802) for $\mathrm{G}_{1}$; whereas this pattern is slightly more blurry, compared to the nonirradiated steel (Figure 6), its quality was sufficient for the stress/strain and GND evaluation.

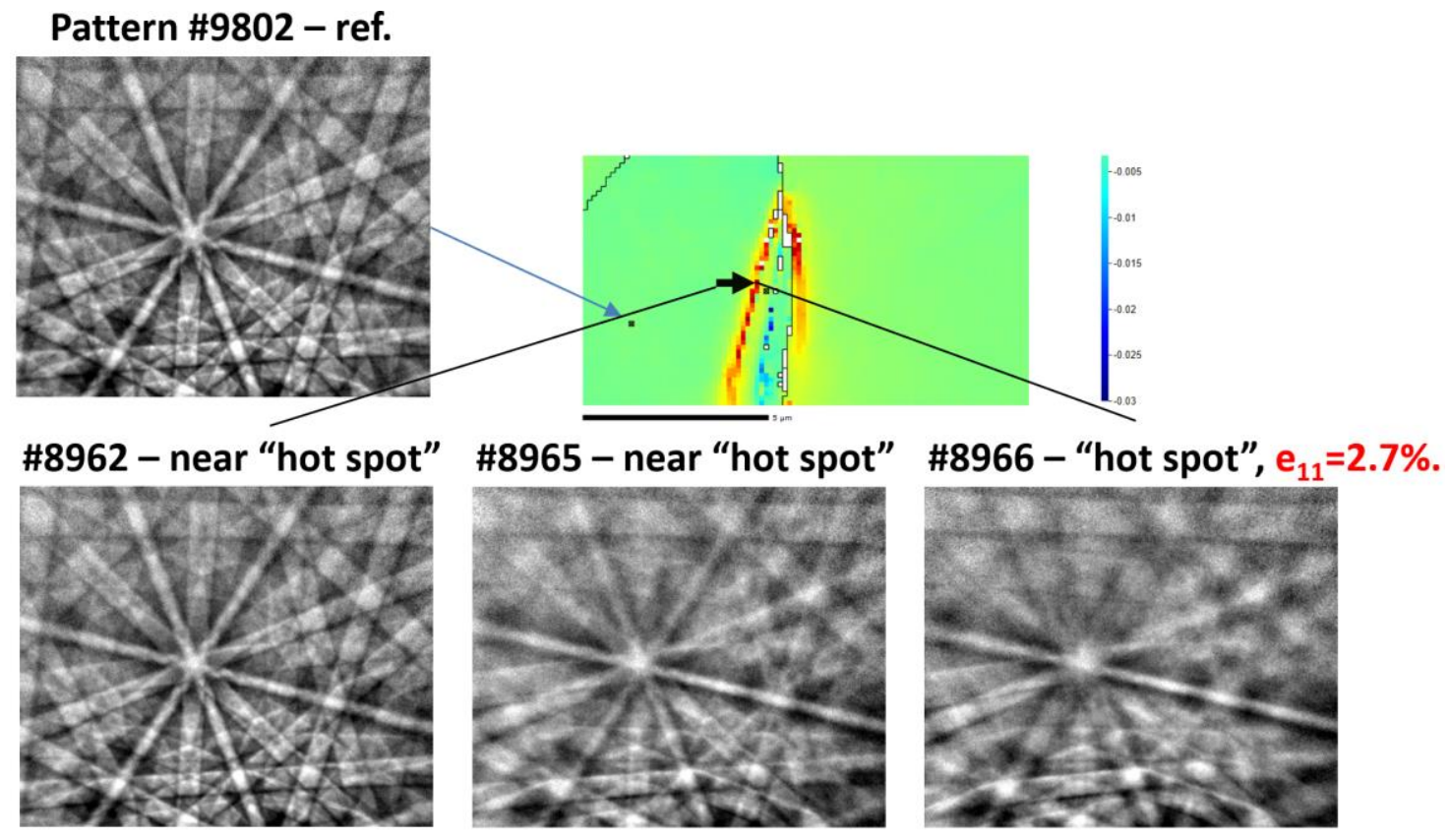

Figure 26. Pattern degradation inside strain localization areas as an issue. Pattern quality may vary drastically within one to two steps $(125-250 \mathrm{~nm})$.

Pattern \#8962, near the hot spot, was of an acceptable quality; however, pattern \#8965 ( 375 nm from the previous one) showed strong degradation. The Kikuchi lines became very blurry, and weak secondary lines almost disappeared. The next pattern inside the hot spot showed further degradation. For many points inside the hot spot, the HR-EBSD analysis ran into the data processing issue, suggesting unreasonably high elastic strains in the lattice, of $\sim 2-3 \%$. Such points in most cases are accompanied by low values of cross-correlation function (i.e., the geometric mean of XCF peak height, the analogy of 
confidence index) and can be filtered out easily. Being consistent and stable for most of the dataset, the current numerical HR-EBSD algorithms need further development and enhancement to handle strong spatial variations in the pattern quality observed in the irradiated and deformed steel. This task is difficult to handle within the framework of the present project. In general, however, the results show that HREBSD provides a way to study strain-induced phenomena in irradiated materials at the grain and subgrain levels.

\section{SUMMARY AND CONCLUSIONS}

This report documents the results of pilot HR-EBSD in situ tensile tests with neutron-irradiated steel specimens. Miniature irradiated specimens of custom geometry were manufactured from available irradiated material (304L austenitic steel, $\sim 10.7 \mathrm{dpa}$ ) and prepared to the mechanical tests via standard metallography procedures and electropolishing.

An advanced HR-EBSD analysis was conducted using datasets recorded during in-situ mechanical tests, at different stress and strain levels, allowing for tracking and quantifying local changes in the structure. Changes in the GND density were reliably observed at load levels below the yield stress. The GND values changed inside the dislocation channels, near GBs, and in the grain interior, far from the influence of dislocation channels. Interestingly, the GND density histogram had a shape of a log-normal distribution prior straining, as well as at small strain levels.

It was demonstrated that the HR-EBSD approach provides a high level of details regarding channel-GB interaction events: strain and stress tensor components, as well as spatial GND variations. Pattern quality degradation was found to be an issue during testing of irradiated materials. Kikuchi pattern quality decreased inside the hot spots even at overall plastic strains of $\sim 1-2 \%$. Pattern degradation may require some additional development and modifications in the numerical HR-EBSD algorithms.

The tests reported here show that the HR-EBSD approach allows for addressing the problem of internal stresses in irradiated materials such as LWR components and provides insight at the grain level, covering statistically significant areas (tens or even hundreds of grains). This information is important for understanding mechanistic processes and developing predictive models of crack initiation. Further experimental work may include testing high-dose materials, including materials irradiated in service.

\section{ACKNOWLEDGMENTS}

This manuscript has been authored by UT-Battelle, LLC, under contract DE-AC05-00OR22725 with the US Department of Energy. The US government retains and the publisher, by accepting this manuscript for publication, acknowledges that the US government retains a nonexclusive, paid-up, irrevocable, worldwide license to publish or reproduce the published form of this manuscript or allow others to do so, for US government purposes.

The research was supported by the US Department of Energy, Office of Nuclear Energy, for the Light Water Reactor Sustainability Program research and development effort. The experimental work was partially supported by a Nuclear Science User Facilities Rapid Turnaround Experiment grant. Help and support from D. Dingley (BLG Vantage) in discussing the HR-EBSD approach and HR-EBSD datasets are gratefully acknowledged. The authors would like to thank Dr. A. Nelson (ORNL) and Dr. X. Chen (ORNL) for reviewing the report and providing valuable comments and suggestions, and L. Varma (ORNL) for help with document preparation. 


\section{REFERENCES}

[1] M. Sauzay, K. Bavard, and W. Karlsen, "TEM observations and finite element modelling of channel deformation in pre-irradiated austenitic stainless steels-Interactions with free surfaces and grain boundaries," Journal of Nuclear Materials, vol. 406, 2010, pp. 152-165.

[2] M. Sauzay and M.O. Moussa, "Prediction of grain boundary stress fields and microcrack initiation induced by slip band impingement," Fracture Phenomena in Nature and Technology, Springer, 2014, pp. 215-240.

[3] E. Plancher, J. Petit, C. Maurice, V. Favier, L. Saintoyant, D. Loisnard, N. Rupin, J.-B. Marijon, O. Ulrich, M. Bornert, and others, "On the accuracy of elastic strain field measurements by Laue microdiffraction and high-resolution EBSD: A cross-validation experiment," Experimental Mechanics, vol. 56, 2016, pp. 483-492.

[4] K. Fukuya, "Current understanding of radiation-induced degradation in light water reactor structural materials," Journal of Nuclear Science and Technology, vol. 50, 2013, pp. 213-254.

[5] K. Fukuya, M. Nakano, K. Fujii, and T. Torimaru, "IASCC susceptibility and slow tensile properties of highly-irradiated 316 stainless steels," Journal of nuclear science and technology, vol. 41, 2004, pp. 673-681.

[6] Z. Jiao and G. Was, "Impact of localized deformation on IASCC in austenitic stainless steels," Journal of Nuclear Materials, vol. 408, 2011, pp. 246-256.

[7] M.N. Gussev, K.G. Field, and J.T. Busby, "Deformation localization and dislocation channel dynamics in neutron-irradiated austenitic stainless steels," Journal of Nuclear Materials, vol. 460, 2015, pp. 139-152.

[8] K.J. Stephenson and G.S. Was, "The role of dislocation channeling in IASCC initiation of neutron irradiated stainless steel," Journal of Nuclear Materials, vol. 481, 2016, pp. 214-225.

[9] T. Britton, J. Jiang, R. Clough, E. Tarleton, A. Kirkland, and A. Wilkinson, "Assessing the precision of strain measurements using electron backscatter diffraction-Part 2: experimental demonstration," Ultramicroscopy, vol. 135, 2013, pp. 136-141.

[10] A.J. Wilkinson and T.B. Britton, "Strains, planes, and EBSD in materials science," Materials today, vol. 15, 2012, pp. 366-376.

[11] J. Jiang, T.B. Britton, and A.J. Wilkinson, "Evolution of dislocation density distributions in copper during tensile deformation,” Acta Materialia, vol. 61, 2013, pp. 7227-7239.

[12] J. Jiang, T.B. Britton, and A.J. Wilkinson, "Accumulation of geometrically necessary dislocations near grain boundaries in deformed copper," Philosophical Magazine Letters, vol. 92, 2012, pp. $580-588$.

[13] T. Vermeij and J.P.M. Hoefnagels, "A consistent full-field integrated DIC framework for HREBSD," Ultramicroscopy, vol. 191, 2018, pp. 44-50.

[14] M. Ojima, Y. Adachi, S. Suzuki, and Y. Tomota, "Stress partitioning behavior in an fcc alloy evaluated by the in situ/ex situ EBSD-Wilkinson method," Acta Materialia, vol. 59, 2011, pp. 4177-4185.

[15] M. Ojima, J. Inoue, S. Nambu, P. Xu, K. Akita, H. Suzuki, and T. Koseki, "Stress partitioning behavior of multilayered steels during tensile deformation measured by in situ neutron diffraction," Scripta Materialia, vol. 66, 2012, pp. 139-142.

[16] D.C. Johnson, B. Kuhr, D. Farkas, and G.S. Was, "Quantitative linkage between the stress at dislocation channel - Grain boundary interaction sites and irradiation assisted stress corrosion crack initiation," Acta Materialia, vol. 170, 2019, pp. 166-175.

[17] D. Johnson, B. Kuhr, D. Farkas, and G. Was, "Quantitative analysis of localized stresses in irradiated stainless steels using high resolution electron backscatter diffraction and molecular dynamics modeling," Scripta Materialia, vol. 116, 2016, pp. 87-90.

[18] Localized Deformation Investigation in Irradiated Materials via Electron Microscopy and In Situ Testing, ORNL/TM-2017/507, 2017. 
[19] M.N. Gussev and K.J. Leonard, "In situ SEM-EBSD analysis of plastic deformation mechanisms in neutron-irradiated austenitic steel," Journal of Nuclear Materials, vol. 517, 2019, pp. 45-56.

[20] M.N. Gussev, K.G. Field, and J.T. Busby, "Strain-induced phase transformation at the surface of an AISI-304 stainless steel irradiated to $4.4 \mathrm{dpa}$ and deformed to $0.8 \%$ strain," Journal of Nuclear Materials, vol. 446, 2014, pp. 187-192.

[21] J. Massoud, P. Dubuisson, P. Scott, and V. Chamardine, "CIR II program: description of the Boris 6 and 7 experiments in the BOR-60 fast breeder reactor," EPRI Report, vol. 1011787, 2005.

[22] B. Cockeram and K. Chan, "In situ studies and modeling of the deformation and fracture mechanism for wrought Zircaloy-4 and Zircaloy-2 as a function of stress-state," Journal of Nuclear materials, vol. 434, 2013, pp. 97-123.

[23] A. Arsenlis and D. Parks, "Crystallographic aspects of geometrically-necessary and statisticallystored dislocation density," Acta materialia, vol. 47, 1999, pp. 1597-1611.

[24] Y.A. Abzaev, "Evolution of Distribution of Dislocations in Ni 3 Ge Single Crystals During Deformation," Russian physics journal, vol. 46, 2003, pp. 504-509.

[25] G.M. de Bellefon and J. van Duysen, "Finite element analysis of the influence of elastic anisotropy on stress intensification at stress corrosion cracking initiation sites in fcc alloys," Journal of Nuclear Materials, vol. 503, 2018, pp. 22-29. 